NASA Technical Memorandum 105161

NASA Lewis Steady-State

Heat Pipe Code

Users Manual

Leonard K. Tower

Sverdrup Technology, Inc.

Lewis Research Center Group

Brook Park, Ohio

Karl W. Baker

National Aeronautics and Space Administration

Lewis Research Center

Cleveland, Ohio

and

Timothy S. Marks

Oregon State University

Corvallis, Oregon

June 1992

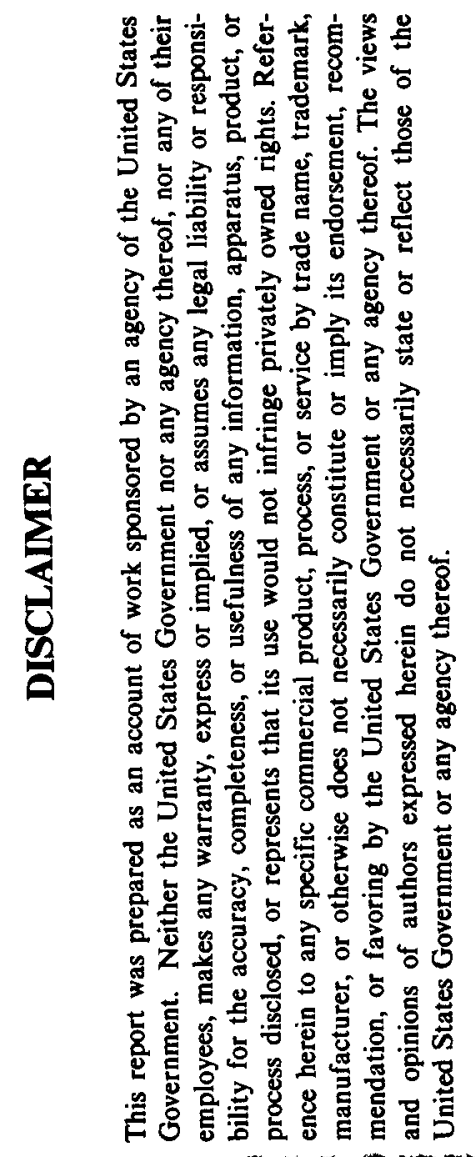




\section{DISCLAIMER}

This report was prepared as an account of work sponsored by an agency of the United States Government. Neither the United States Government nor any agency Thereof, nor any of their employees, makes any warranty, express or implied, or assumes any legal liability or responsibility for the accuracy, completeness, or usefulness of any information, apparatus, product, or process disclosed, or represents that its use would not infringe privately owned rights. Reference herein to any specific commercial product, process, or service by trade name, trademark, manufacturer, or otherwise does not necessarily constitute or imply its endorsement, recommendation, or favoring by the United States Government or any agency thereof. The views and opinions of authors expressed herein do not necessarily state or reflect those of the United States Government or any agency thereof. 


\section{DISCLAIMER}

Portions of this document may be illegible in electronic image products. Images are produced from the best available original document. 


\title{
NASA LEWIS STEADY-STATE HEAT PIPE CODE USERS MANUAL
}

\author{
Leonard $\mathrm{K}$. Tower \\ Sverdrup Technology, Inc. \\ Lewis Research Center Group \\ Brook Park, Ohio 44142 \\ Karl W. Baker \\ National Aeronautics and Space Administration \\ Lewis Research Center \\ Cleveland, Ohio 44135 \\ and \\ Timothy S. Marks \\ Oregon State University \\ Corvallis, Oregon 97331
}

\begin{abstract}
SUMMARY
The NASA Lewis heat pipe code has been developed to predict the performance of heat pipes in the steady state. The code can be used as a design tool on a personal computer or, with a suitable calling routine, as a subroutine for a mainframe radiator code. A variety of wick structures, including a user input option, can be used. Heat pipes with multiple evaporators, condensers, and adiabatic sections in series and with wick structures that differ among sections can be modeled. Several working fluids can be chosen, including potassium, sodium, and lithium, for which the monomer-dimer equilibrium is considered. The code incorporates a vapor flow algorithm that treats compressibility and axially varying heat input. This code facilitates the determination of heat pipe operating temperatures and heat pipe limits that may be encountered at the specified heat input and environment temperature. Data are input to the computer through a user-interactive input subroutine. Output, such as liquid and vapor pressures and temperatures, is printed at equally spaced axial positions along the pipe as determined by the user.
\end{abstract}

\section{INTRODUCTION}

The NASA Lewis Research Center is conducting research programs involving power production for space applications. Systems being considered may employ heat pipes either to conduct heat from the source to the power converter or to remove waste heat to radiators. It was desired to extend the capabilities of current steady-state codes (refs. 1 to 3 ) in order to perform the design and analysis required for evaluating systems of interest. Hence new computation algorithms were derived and a new code was written that incorporates portions of an existing Lewis code (ref. 3 ). This code has features that should enhance its execution speed and precision.

An important requirement was a vapor flow algorithm that could treat compressibility and axially varying heat input in a satisfactory manner yet be concise enough to function on a microcomputer of limited capacity and speed. Finite difference techniques, which had been used effectively in fundamental studies of heat pipe vapor dynamics (refs. 4 and 5), were eliminated by the latter consideration. Also desired was great flexibility in the input of boundary conditions and other parameters, so that a wide variety of cases could be computed. We believe that for our purposes this code represents an improvement over other similar codes. 
A listing of the NASA Lewis heat pipe code is available from the Computer Software Management and Information Center, Athens, Georgia 30602. Because of possible updates of the code, the results of example cases run using the listing code may differ slightly from those presented herein.

The authors are indebted to Barbara McKissock and Carlos Rodriguez for their help and patience in running the code during the debugging process.

\section{DISCUSSION}

Guidelines established for the Lewis code were, among others, a simple, logical, modular structure and extensive documentation. Also, a code was sought that could be used as a design tool on a personal computer (PC) or, with a suitable calling routine, as a subroutine for a mainframe radiator code.

The Lewis code currently has about 45 subroutines, each providing a limited function, that are controlled by a few master calling routines. This structure makes program flow easy to interpret. Moreover, it facilitates the replacement or updating of subroutines and the addition of new ones. Most of the required physical parameters, wick resistance for example, are computed from input specifications for particular types of structures by using accepted formulas, as in other codes. For the benefit of the user who wishes to consider internal structures outside of the repertory included, provision is made for user input of the required physical parameters.

The general features of the code are described first, followed by a brief discussion of its functioning. Appendix A presents a list of symbols appearing in the input and output of the code. Appendix B contains a discussion of the vapor flow algorithm employed. Appendix C describes and illustrates the user-interactive data entry for an example case, while appendix $D$ describes the data output for the example. Appendix $E$ gives the output for another example case. Appendix $F$ summarizes the significance of the various heat pipe limits. The code was written in Fortran 77 and compiled with Microsoft Fortran 4.1.

\section{Summary of Code Features}

The code has been constructed for straight, cylindrical heat pipes with no bends. Simple modification to noncircular cross sections could be achieved by using the hydraulic radius approach, but this feature is not currently implemented. Curvature, but no sharp bends, is permissible. Operation in the presence of gravitational fields is accounted for in the case of straight pipes, but thermosyphons are not included.

The heat pipe can be subdivided into as many as 20 sections, far more than will normally be required. These sections can be heat input or evaporator sections, adiabatic sections, and heat removal or condenser sections, mixed in any manner provided that the first section is a heat input section. The nature of any section is indicated by the type of boundary condition data that is entered for that section.

At present the following options are available for the boundary conditions: (1) specified heat input or removal rate at the pipe exterior surface and (2) specified environment temperature external to the pipe, with heat transfer conditions from the pipe surface to the environment provided by the user. 
For each section the required data can be entered as single values pertaining to the entire section. Values of the input parameters can also be entered at as many as 20 points spaced along the section, with a different magnitude at each point.

Computations along the pipe are made by a Runge-Kutta routine for which the initial step size is chosen, with automatic reduction or increase as the slope of the principal dependent variable, pressure, exceeds or falls below certain bounds.

Data input is by means of an interactive subroutine that queries the user concerning the options to be employed in the case to be run. For output the user can select the number of uniformly spaced points along the pipe axis at which the principal variables will be printed out. The spacing of these points need not correspond with the step size chosen for the Runge-Kutta solution. The printout is furnished after thermal convergence of the solution has been obtained. When a heat pipe limit is encountered during the solution that does not cause the solution to halt, the type of limit is printed out with the solution. The data printed out can be output directly to a plotting device if a suitable plotting utility is available and the necessary changes are made in the source code.

\section{Subdivisions of Heat Pipe}

To clarify the various types of subdivisions of the heat pipe, consider this illustration of a heat pipe, with two evaporators separated by an adiabatic section, and a condenser:

Pipe sections.-The major subdivisions are the pipe sections, which can be evaporator, adiabatic section, and condenser in the usual terminology. So that other than the usual sequence of boundary conditions can be employed, this nomenclature is not used in the code. Rather, the pipe is conceived to be divided into NS sections numbered IS $=1$ to NS. The function of each section is denoted by the type of boundary condition imposed at the time of data input. The number of sections is limited to 20.

Uniform boundary conditions pertaining to the entire section can be entered at the time of data input. Alternatively, varying conditions can be entered at I locations along each section numbered IS. The total of such locations for each section is designated by NH(IS), where NH(IS) must be less than 21. At any section end that abuts another section, the same physical coordinate can have two boundary conditions associated with it: one pertaining to the section ending, the other to the next section.

Runge-Kutta steps.-The initial number of steps, ISTEP, that are employed in the Runge-Kutta solution is chosen by the user. This choice determines the maximum step size to be employed in the program. When the pressure drop between two successive steps exceeds about 3 percent, the subsequent step size is subject to automatic halving during execution. This is particularly important when conditions change rapidly as choking is approached. Similarly if the pressure increase is less than 1 percent, the step size is doubled unless the maximum step size has been reached. Also, when the end of a section is approached, the step size is adjusted so that a step coincides with the end of each section.

Print locations. - For purposes of data output the user can choose the number of equally spaced locations, numbered IP, along the pipe at which data will be printed out after a solution has been obtained. The total number of such locations is IPSTEP +1 , where IPSTEP is less than 101. For all locations at which a print location and a Runga-Kutta step do not coincide, the data for printing are linearly interpolated between the adjacent Runge-Kutta steps. Also printed out in the proper axial 
sequence are the data pertaining to the beginning and end of each section whether or not these correspond with a chosen print location. Except for the pipe beginning and end, there will be two listings of data with the same axial coordinate at each such section change.

\section{Boundary Conditions in Sections}

Each section of the pipe can have imposed on it one of three boundary conditions: (1) specified heat input at the exterior surface, (2) temperature at the exterior surface, and (3) environment source or sink temperature. Options 1 and 3 are fully implemented at this time, but option 2 is not.

Option 1, specified heat input, requires information on heat input. For sections with uniform radial heat input, only the total heat in watts for the section is required. If the radial heat input varies along the section, the input rate in watts per meter at as many as 20 points along the section can be entered. The cubic spline interpolation produces a smooth fit of the data. A section with no heat input will be an adiabatic section.

Option 3, specified environment source or sink temperature, requires that parameters pertaining to heat transfer between the pipe surface and the environment be provided. In the case of radiation these are the specific area of the pipe surface in square meters per meter of length and a radiation constant that combines the view factor and the effective emissivity. In the case of convection or conduction a suitable heat transfer coefficient must be provided. Combined convection and radiation in a section can be handled. Again these data can be entered as single values for an entire section. If there is variation along the section the data can be entered at several points, with spline interpolation being used to provide a smooth fit between the points.

A pipe can have sections with both options for heat input or both options for heat removal. For example, a section with prescribed heat input and a section with heat gain from a source by radiation can be present in the same pipe.

The user should be aware that not all conditions can be handled. There is an obvious requirement that any heat pipe have at least one heat input section and one heat removal section. Furthermore some choices of boundary conditions may result in an encounter with one of the heat pipe limits, necessitating a change in the dimensions or the working fluid.

\section{Spline Interpolation of Input Data}

The flexibility of the program is enhanced greatly by the use of cubic spline interpolation of some of the input data. With this approximation, data that are expected to be continuous but varying with position in a section need be entered for only a few points. Coefficients are then determined that enable the data to be interpolated smoothly at any axial location within the section. Among the data that use the spline fit are the radiation parameters and convective heat transfer coefficients for the pipe surface. Specified heat input that varies with position in the section can also be interpolated by the spline fit provided that the change within the section is smooth. The algorithms to implement the spline interpolation were adapted from reference 6. 


\section{Material and Working Fluid Choices}

The code contains thermal conductivity data for the following wall and wick materials: aluminum, beryllium, copper, Inconel, iron, molybdenum, nickel, niobium-1\% zirconium, 304 stainless steel, tantalum, titanium, and tungsten. If the material of interest is not in this list, the thermal conductivities of the wall and wick materials can be entered by the user from other sources. Similarly the effective thermal conductivity of the fluid-saturated wick can be entered in the user-input wick property section of the code. The properties so entered will be for some estimated mean operating temperature of the pipe and will be subject to correction.

The following working fluids are provided in the code: alkali metals (lithium, potassium, sodium, and cesium) and other fluids (ammonia, methanol, mercury, Dowtherm A, acetone, benzene, Freon-11, $\mathrm{n}$-heptane, silver, toluene, and $\mathrm{m}$-xylene).

\section{Thermodynamic Data for Working Fluids}

Alkali liquid metals.-The alkali liquid-metal vapor contains monatomic (monomer), diatomic (dimer), and tetrameric species (ref. 7). The Lewis heat pipe code requires that the monomer and dimer species be accounted for in computing the composition and thermal properties of the working fluid.

The required thermodynamic data for the alkali metals were taken from reference 8 . Reference 8 presents polynomial least-squares fits for the specific heats of the solid, liquid, and gaseous species as a function of temperature. The data for the gaseous species pertain to the ideal-gas state of the individual species. Reference 8 also lists the enthalpies and entropies of the species relative to the atomic constituents, assigned at a standard temperature. The polynomial coefficients and the reference enthalpies and entropies are stored in the heat pipe code as block data.

By using the polynomial coefficients and the assigned thermal data, the specific heat, enthalpy, and Gibbs free energy of each species can be computed as a function of temperature. A call to one of the thermal data subroutines at a specified temperature determines such properties as the composition of the vapor, the heat of vaporization, the vapor pressure, the speed of sound, and several first partial derivatives used in the code.

In computing the properties the assumption is made that the vapor behaves as a mixture of ideal, but reacting, gases. This approach is similar to one described in reference 9 and referred to as the "quasi-chemical equation of state." The assumption was made in reference 9 that monomeric, dimeric, and tetrameric species were present as ideal gases, but the data were fitted to an experimentally determined PVT diagram. In the present code the source of the thermal data is a tabulation of properties for gaseous species that is based upon spectroscopic data. The tetramers, present in only a small fraction of the dimer concentration, are neglected. Computations of vapor pressure and heat of vaporization that are made by using the algorithm of the Lewis code agree with tabulations from other sources (refs. 10 and 11). Agreement is within 4 percent, which is within experimental error for data taken on heat pipes.

Thermodynamic data for other working fluids.- Thermodynamic data for the other fluids are from references 10 and 11 . 


\section{Physical Property Data}

The conductivities of the solid materials and the physical properties of the working fluids are from references 10 to 15 .

Flow Algorithms

Vapor flow algorithm.-The vapor flow algorithm employed in the code was rederived for compressible flow from expressions for incompressible flow by Busse (ref. 16). Appendix B contains the derivation presented in NASA CR-185179 (ref. 17), with additions and corrections.

For alkali metal working fluids, chemical equilibrium exists among the monomeric and dimeric gaseous species. No tangential velocity component exists at the liquid-vapor interface, and the radial pressure gradient may be neglected.

The incompressible Busse equations (ref. 16) have been rederived as compressible relations for use in the present code as shown in appendix B. The change in pressure and the Busse velocity profile factor, which adjusts the Poiseuille profile, are computed at each step with density variation considered. In addition, for alkali liquid metals the mean gas temperature, which is different from the saturated vapor-liquid temperature, is also determined at each step, by means of an energy integral approach. For these working fluids, large temperature differences can exist between the liquid-vapor interface and the core of the vapor (ref. 5). However, for these fluids the mean vapor temperature and the vapor-liquid interface temperature are equated beyond the point in the condenser where they become equal. For all working fluids at peak Mach numbers less than 0.01, Busse's incompressible relations are employed, and the density at the end of each Runge-Kutta step is updated in a procedure similar to that employed in reference 1 for all Mach numbers. In this way a mathematical problem was avoided at conditions where the change in pressure and density is extremely small.

At this time the assumption is made of laminar flow though the pipe. Studies (ref. 18) have shown that in regions of vapor injection, as in the evaporator, turbulence is suppressed at axial Reynolds numbers of up to 1 million. In regions of vapor extraction (condenser), turbulence is induced. A reliable theory as to the axial rate at which turbulence develops would be required for this effect to be incorporated into the code. Many other uncertainties concerning the condenser exist, such as recirculation and droplet nucleation. An attempt to account for turbulence would seem premature until sufficient experimental data are available to clarify this region better.

Liquid flow algorithm.-Liquid pressure drop is computed by means of the familiar Darcy equation (ref. 10). Multiple axial liquid paths of differing permeability can be accounted for, as in artery structures. Hydrostatic pressure changes due to tilting of the pipe in gravity fields are considered.

\section{Wick Structure Options}

There are six wick options in the code: user input, screen wick, screen wick with arteries, sintered metal, sintered metal with arteries, and longitudinal grooves (not implemented).

The user must select one of these options. Figure 2 shows the wick structures that are incorporated in the code. The user input option, which is not shown in figure 2 , has been incorporated to 
allow the user to analyze heat pipes with wick structures other than those listed. The user input option requires the following data:

(1) The wick permeability to fluid flow multiplied by the wick cross-sectional area perpendicular to fluid flow

(2) The perimeter of the wick at the liquid-vapor interface

(3) The porosity of the wick

(4) The effective thermal conductivity of the wick

(5) The effective vapor area perpendicular to the axis

(6) The minimum effective capillary radius

(7) The entrainment critical dimension

(8) The minimum nucleation radius

Option 2 is for screen wick structures as shown in figure 2. The screen wick option requires the following input data:

(1) The diameter of the screen wire

(2) The width of space between screen wires

(3) The crimping factor

(4) The number of screen wraps

Option 3 can be used for screen wicks with arteries. This case requires the data from option 2 plus the following:

(1) The artery external diameter

(2) The artery wall thickness

(3) The number of arteries

Option 4 can be used to analyze heat pipes with sintered-metal wick structures. This option requires the following data:

(1) The porosity of the wick (the volume of liquid in the wick divided by the total volume of the wick)

(2) The effective radius of the wick particles

(3) The thermal conductivity experimental constant, which is 0.34 for metal felt or fiber and 0.53 for sintered powders. The experiments and the derivation of the thermal conductivity equation are outlined in reference 10 .

(4) The thickness of the wick

Option 5 can be used for sintered wicks with arteries. This case requires the data from option 4 plus the following:

(1) The artery inside diameter

(2) The number of arteries

(3) The protrusion area of each artery into the vapor space, which is used to account for the reduction in vapor flow area caused by the arteries as shown in figure 2

Option 6 is for heat pipes with longitudinal grooves. This option has not been implemented at this time. 


\section{FUNCTIONING OF CODE}

This section describes in general terms how the code operates. Figure 3 shows a very simplified flow chart with only major subroutines. After the user calls up the code by typing LERCHP, subroutine INPUT is called. Data are entered from the keyboard as described in the following section. At the completion of data input, subroutine RUNCAS is called. This subroutine controls the flow of execution. First it calls subroutine GUESS, in which an initial guess is made of the evaporator surface temperature at the beginning of the pipe T4E. The code uses all the heat input, environment temperature, radiation parameter, and heat transfer coefficient information that has been provided in INPUT to make this guess. RUNCAS then calls subroutine START, which initializes other temperatures at the various radial locations at the beginning of the pipe. If the estimate of $T 4 E$ is near the critical temperature of the working fluid at the outset, the user is returned to INPUT.

Following this, RUNCAS begins an iteration to determine the operating condition of the heat pipe. Subroutine SUMEP is called. This computes the pressure, temperatures, and axial heat flux along the pipe by using a Runge-Kutta algorithm presented in reference 19 . When the computation along the entire pipe length is completed, the axial heat flux at the downstream end of the pipe should be zero. If this is not the case, a correction to $\mathrm{T} 4 \mathrm{E}$ is estimated and the iteration continues until the residual axial heat flux is less than $0.01 \%$ of the heat input. During each iteration the flow is monitored for the sonic condition. If this is encountered before reaching the downstream end of the last heat input or adiabatic section, $\mathrm{T} 4 \mathrm{E}$ is raised to the minimum value needed to move this sonic point to the end of the section. The iteration is begun again at the beginning of the pipe. The flow is monitored for the viscous limit by comparing the vapor pressure computed at any point to the pressure at the evaporator end cap. If the ratio is less than 0.1 , execution is terminated and a message is printed instructing the investigator to provide new input conditions. Alternatively, a viscous limit is deemed to be present if no temperature can be found at which the entire condenser length will reject heat.

After convergence is reached, the data print subroutine is called. Data are printed out at the chosen axial positions along the pipe, and at the beginning and end of each pipe section. A new data input is then requested.

\section{Description of Data Input}

In the present $\mathrm{PC}$ version of the program, parameter input is by means of an interactive subroutine. The user is queried concerning pipe geometry, wick data, and choice of working fluid. This section demonstrates the operation of the code. Note that in this and following sections of this manual, statements written to the screen or to the printer from the code are written in upper case. Narrative comments about these statements are written in lower case. These comments only appear herein and are not printed by the code. The input data for an example case, without the descriptive material, appear in appendix $\mathbf{C}$.

The executable version of the code is file LERCHP.EXE, which stands for Lewis Research Center Heat Pipe. The suffix EXE means that the file is an executable file. The executable version of the code is started by typing LERCHP at the system operating level. The code will respond by typing the following statement on the screen and the printer: 


\section{LEWIS HEAT PIPE CODE, NASA LEWIS RESEARCH CENTER}

The code prints out input data to the printer periodically as the user goes through the input subroutine.

\section{IS THE HEAT PIPE OPERATING IN A "G" FIELD? TYPE "Y"}

The code asks the user if the heat pipe is operating in a $\mathrm{G}$ field. If the answer to this question is no, hit the Enter key or answer with $\mathbf{N}$. The code will then assume that the heat pipe is operating in zero gravity. If the answer to this question is yes, the following message is printed:

\section{“G" FIELD STRENGTH, FRACTIONS OF "G" $\quad 0.00000000$} IF CHANGE, TYPE "Y”, THEN PRESS ENTER

The G fields for heat pipes operating on Earth, the Moon, and Mars are 1.0. 0.17, and 0.33, respectively.

\section{BEGIN INPUT OF HEAT PIPE GEOMETRY}

NUMBER OF RUNGE-KUTTA STEPS CHOSEN.

The number entered here will correspond to calculation points along the heat pipe axis. The default value is 100 , but more Runge-Kutta steps may be introduced as needed to avoid large changes in conditions from one point to the next.

\section{LIMIT ON DATA POINTS PRINTED IS 100. SHOULD NOT EXCEED NUMBER OF RUNGE-KUTTA STEPS. NUMBER OF DATA POINTS PRINTED ALONG THE PIPE 50 IF CHANGE, TYPE "Y", THEN PRESS ENTER}

The default value for print output of calculation results is 50 out of a possible 100 points.

NUMBER OF PIPE SECTIONS TO BE CONSIDERED IF CHANGE, TYPE "Y", THEN PRESS ENTER

This is the total number of heat pipe sections. Sections can be defined as regions of differing thermal boundary conditions or differing structure. The default value is 2 .

\section{ARE PIPE DIMENSIONS AND WICKING SAME IN ALL SECTIONS? TYPE "Y"}

If yes is answered to this question, wick properties for all sections are assumed to be constant, and wick data need only be entered for the first section. The code will assign the same input data to all other sections. If the wick structure or containment envelop change from one axial location of the heat pipe to another, do not type $\mathbf{Y}$ but press the enter key. In this case the questions listed below will reappear for each section of the pipe. If input is repeated, $\mathbf{Y}$ must be typed in again if the wicking in the pipe sections is the same.

If yes is answered to the preceding question, the following will appear on the screen: 
WICKING AND DIAMETERS ALL SAME AS SECTION 1. OUTSIDE PIPE WALL DIAMETER, DO, $\mathrm{m} \quad \mathbf{. 0 0 0 0 0 0 0}$

IF CHANGE, TYPE “Y”, THEN PRESS ENTER

Input the outside diameter of the containment envelope in meters.

INSIDE PIPE WALL DIAMETER, DI, $\mathrm{m}$ .00000000

IF CHANGE, TYPE "Y", THEN PRESS ENTER

Input the inside diameter of the containment envelope in meters.

WICK TYPE CODE

0

$1=$ USER INPUT DATA

$2=$ SCREEN WICK

3 = SCREEN WITH ARTERIES

4 = SINTERED METAL

5 = SINTERED METAL WITH ARTERIES

$6=$ GROOVES

CHOICE OF WICK CODE

0

IF CHANGE, TYPE “Y”, THEN PRESS ENTER

There are six wick options in the code at this time. There is a section in the manual that describes the input data required for each case. If choice 6 is requested, the user is reminded that this choice is not implemented. In this case the user input option 1 was chosen and the data required are

USER INPUT WICK PROPERTIES.

WICK PERMEABILITY * AREA, AK, m**4

.00000000

IF CHANGE, TYPE "Y”, THEN PRESS ENTER

This is the permeability of the wick to fluid flow in square meters multiplied by the flow area of the wick in square meters.

VAPOR SPARE PERIMETER, PE, m

.00000000

IF CHANGE, TYPE "Y”, THEN PRESS ENTER

This is the perimeter at the liquid-vapor interface in meters.

POROSITY OF WICK, PORE

.00000000

IF CHANGE, TYPE “Y”, THEN PRESS ENTER

Input the volume of liquid in the wick divided by the total volume of the wick.

EFFECTIVE WICK CONDUCTIVITY, KE, W/m K .0000000

IF CHANGE, TYPE "Y”, THEN PRESS ENTER

This is the effective thermal conductivity of the wick filled with fluid, in the radial direction.

EFFECTIVE VAPOR AREA, AV, $\mathrm{m}^{* * 2}$

.00000000

IF CHANGE, TYPE “Y”, THEN PRESS ENTER 
Input the effective cross-sectional area perpendicular to the axis.

EFF. MIN CAPILLARY RADIUS, RCM, m

.00000000

IF CHANGE, TYPE "Y", THEN PRESS ENTER

This is the effective minimum radius of curvature of the meniscus, which is used in calculating the capillary limit.

ENTRAINMENT DIMENSION, DCRITE, $\mathrm{m} \quad \mathbf{. 0 0 0 0 0 0 0 0}$

IF CHANGE, TYPE "Y", THEN PRESS ENTER

Input the critical dimension used to calculate the entrainment limit. See reference 20.

\section{CRITICAL NUCLEATION RADIUS, RN, $\mathbf{m}$ \\ DEFAULT VALUE $=1.0 \mathrm{E}-6$ \\ IF CHANGE, TYPE "Y", THEN PRESS ENTER}

.00000000

The minimum nucleation radius is a parameter used to calculate the boiling limit. This parameter is a function of the surface finish on the inside of the containment envelop. The type of wick structure also has some effect. The boiling limit equation and a description of this parameter can be found in reference 21 .

\section{TO REVIEW OR CORRECT THE INPUT, TYPE "Y"}

If a mistake is made when typing input into the code or if the user wants to review input for errors before a run, typing $\mathbf{Y}$ will allow the user to go back to the beginning of the input. The data values previously entered will be printed out on the screen next to the questions.

Here a summary of the data input up to this point will be output by the printer.

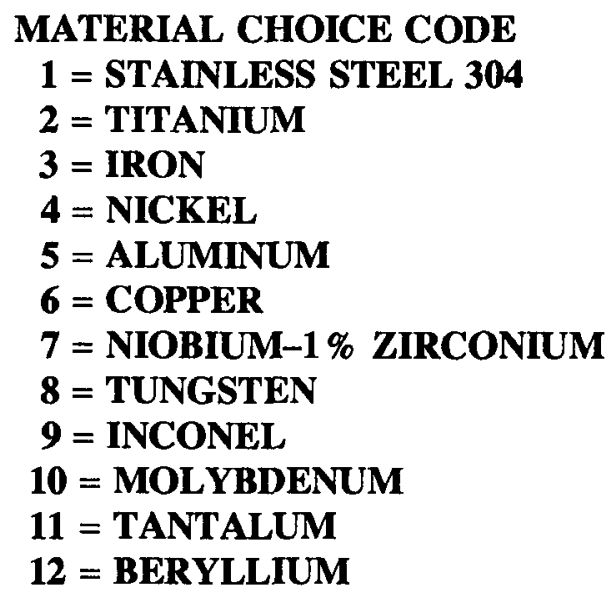

TYPE OF PIPE MATERIAL 0 IF CHANGE, TYPE "Y", THEN PRESS ENTER

Enter the code from the preceding list that corresponds to the material of the heat pipe containment envelope. 
Enter the code from the preceding list that corresponds to the material of the heat pipe wick.

$$
\begin{aligned}
\text { FLUID TYPE CODE } \\
1=\text { LITHIUM } \\
2=\text { POTASSIUM } \\
3=\text { SODIUM } \\
4=\text { WATER } \\
5=\text { AMMONIA } \\
\mathbf{6}=\text { METHANOL } \\
7=\text { MERCURY } \\
\mathbf{8}=\text { DOWTHERM A } \\
\mathbf{9}=\text { ACETONE } \\
10=\text { BENZENE } \\
11=\text { CESIUM } \\
12=\text { FREON-11 } \\
13=\text { N-HEPTANE } \\
14=\text { SILVER } \\
15=\text { TOLUENE } \\
16=\text { M-XYLENE }
\end{aligned}
$$

FLUID TYPE

IF CHANGE, TYPE “Y”, THEN PRESS ENTER

Enter the code from this list that corresponds to the heat pipe working fluid.

WETTING ANGLE, deg $\mathbf{0 0 0 0 0 0 0 0}$

IF CHANGE, TYPE "Y”, THEN PRESS ENTER

Enter the wetting angle, in degrees, of the fluid on the wick material. This value is typically assumed to be 0.0 . In a heat pipe the wetting angle must be less than $90^{\circ}$.

\section{WEBER NUMBER, DEFAULT $2 *$ PI, SEE INSTRUCTIONS 6.2832} IF CHANGE, TYPE "Y", THEN PRESS ENTER

The Weber number is used to determine if the entrainment limit has been reached or exceeded. The Weber number at which entrainment occurs is not well understood in theory and may be different for different heat pipe wick structures. A value of $2 \pi$ is set as the default. This was taken from reference 20.
AVAILABLE CHOICES OF BOUNDARY CONDITIONS FOR SECTIONS
1 HEAT INPUT OR OUTPUT SPECIFIED IN SECTION
2 SURFACE TEMPERATURE SPECIFIED IN SECTION
3 ENVIRONMENT TEMPERATURE GIVEN IN SECTION
CHOICE FOR SECTION \# 1------>0
IF CHANGE, TYPE “Y”, THEN PRESS ENTER 
Choose the boundary condition code that corresponds to the case of interest. This message will be printed out once for each section of the pipe. Option 1 is used when specified heat inputs and outputs are known. Option 2 can be used when surface temperatures and heat transfer data to or from the environment are known, but option 2 currently is not operational. Option 3 is used when the environment temperature and the heat transfer data between the environment and the pipe are specified.

The following input routine is for option 1.

\section{HEAT IN OR OUT ALONG SECTION IS CONSTANT IF CHANGE, TYPE "Y"}

If the heat input to a section, section 1 in this case, is constant along that section, do not type $\mathbf{Y}$, just hit the enter key. Doing this causes the code to assume a constant heat input along the section. The code will then prompt the user for the following:

AXIAL LOCATION OF SECTION BEGINNING, $m \quad \mathbf{0 0 0 0 0 0 0 0}$ IF CHANGE, TYPE "Y"

Zero is normally taken as the upstream end of the evaporator, but it is possible to designate a nonzero value of the axial coordinate as the beginning of the pipe.

AXIAL LOCATION OF SECTION END, $\mathrm{m} \quad \mathbf{. 0 0 0 0 0 0 0}$ IF CHANGE, TYPE "Y"

This position is measured with respect to the chosen zero of the coordinate system.

HEAT INTO OR OUT OF SECTION, $W \quad \mathbf{. 0 0 0 0 0 0 0}$ IF CHANGE, TYPE "Y”

For sections with constant heat input or output, heat is entered in watts. If heat input is not constant along the section of interest, the user should type $\mathbf{Y}$ to the query IF CHANGE, TYPE "Y" following HEAT IN OR OUT ALONG SECTION IS CONSTANT, thusly:

HEAT IN OR OUT ALONG SECTION IS CONSTANT IF CHANGE, TYPE "Y"

Type $\mathbf{Y}$ here and the code will respond with

YOU HAVE CHANGED THE CHOICE TO VARIABLE NUMBER OF SECTION POINTS CONSIDERED----> 0 IF CHANGE, TYPE "Y", THEN PRESS ENTER

The user must enter the number of points along the section where the heat input or output rate is known. After this is done, the code will then ask the user the location and heat transfer rate at each point.

\section{POINT \# 1}

$\mathrm{Z}(1) \quad .00000000$

IF CHANGE, TYPE "Y”, THEN PRESS ENTER 
Input the location where the heat input rate is known. This position is measured with respect to the upstream end of the evaporator.

DQI( 1) .00000000

IF CHANGE, TYPE "Y", THEN PRESS ENTER

Input the heat load in watts per meter of pipe length. It is important to note that an axially varying heat load is entered in watts per meter. However, for sections with constant heat input or output, heat is entered in watts.

If option 3 is chosen, the code will respond

ENVIRONMENT TEMPERATURE, $K \quad \mathbf{. 0 0 0 0 0 0 0}$

IF CHANGE, TYPE "Y", THEN PRESS ENTER

The environment temperature should be entered here. For a radiation heater this would be the heater surface temperature. For a heat pipe that is cooled by radiation heat transfer to space, this temperature would be the effective environment temperature of deep space.

\section{AXIAL LOCATION OF SECTION BEGININING, $m \quad .00000000$ IF CHANGE, TYPE "Y"}

Zero is normally taken as the upstream end of the evaporator, but it is possible to designate a nonzero value of the axial coordinate as the beginning of the pipe.

\section{AXIAL LOCATION OF SECTION END, $m \quad \mathbf{m} \quad \mathbf{0 0 0 0 0 0 0 0}$} IF CHANGE, TYPE "Y”

This position is measured with respect to the chosen zero of the coordinate system.

\section{SPECIFIC AREA PER UNIT LENGTH, SA $\quad \mathbf{0 0 0 0 0 0 0 0}$}

IF CHANGE, TYPE "Y”, THEN PRESS ENTER

This is the area in square meters per meter of axial distance from which the heat pipe either absorbs or radiates heat. If a heat pipe has fins attached to the condenser section, the specific radiating area would be the area of the fins plus the area of the pipe for $1 \mathrm{~m}$ of length.

\section{RADIATION FACTOR, RADK}

IF CHANGE, TYPE "Y", THEN PRESS ENTER

.00000000

The radiation factor RADK is used to account for the effective emissivity of the pipe and fin surfaces. This parameter is also used to account for overall view factors and fin efficiency between the heat pipe and fin surfaces.

\section{CONVECTION COEFFICIENT, HC, W/m**2*K} IF CHANGE, TYPE "Y", THEN PRESS ENTER

\section{.00000000}

This is the value of the convection coefficient between the heat pipe wall and the environment temperature input. 
After boundary conditions have been entered for all the sections of the pipe, the following message will appear:

\section{TO REVIEW OR CORRECT MATERIALS, FLUID, BOUNDARY CONDITIONS, TYPE "Y"}

If a mistake is made when typing input in the code or if the user wants to review input for errors before a run, typing "Y" here will allow the user to go back to the point at which material choices are inserted. The data values previously entered will be printed out on the screen next to the questions.

After this point a summary of the data input up to this point will be output by the printer. After the input has been printed, the code will respond with

\section{COMPUTING----.-->}

\section{Description of Data Output}

After a solution has been obtained, the operator is queried:

\section{DO YOU WISH TO OMIT PRINTOUT OF DATA ALONG THE PIPE? TYPE Y}

Data will not be printed out along the pipe. Rather, a summary of the upstream evaporator and downstream condenser temperatures will be printed. Otherwise the printer will send the message

\section{BEGIN PRINTOUT OF RESULTS}

After this message, data will be printed at the user-specified points. Variable names and the corresponding numeric values are printed. Dimensions are omitted. A table describing the variable names and dimensions is given in appendix $A$. Also see appendixes $D$ and $E$ for example output cases.

Output will be generated at the printer for each run. It includes the following:

(1) All user inputs

(2) Calculated heat transport

(3) Liquid pressures

(4) Vapor pressures

(5) Interpretive messages

Values for the following parameters are given for each printout point in a section:

(1) Axial location

(2) Liquid and vapor pressures

(3) Liquid-vapor interface, outer surface, and mean vapor temperatures

(4) Mean vapor velocity

(5) Mean Mach number

(6) Velocity profile factor

(7) Radial heat input or output per unit length

(8) Axial vapor heat flux 


\section{APPENDIX A}

\section{SYMBOLS USED IN INPUT AND OUTPUT}

A Busse velocity profile parameter

AK product of wick cross-sectional area and permeability, $\mathrm{m}^{4}$

AV cross-sectional area of vapor passage, $\mathrm{m}^{2}$

DELTCR temperature drop through evaporator wick for initiation of boiling, $\mathrm{K}$

DCRITE entrainment critical dimension, $m$

DI inner diameter of pipe wall, $m$

DO outer diameter of pipe wall, $\mathrm{m}$

DQDZ radial heat input into or out of pipe per unit length, $\mathrm{W} / \mathrm{m}$

HC heat transfer coefficient, $\mathrm{W} / \mathrm{m}^{2} \mathrm{~K}$

KE effective thermal conductivity of liquid-saturated wick, W/m K

MACHM mean Mach number at axial position $\mathrm{Z}$ computed by using the mean velocity VM, with sound speed computed from mean temperature TM

NA number of arteries

P vapor pressure at axial position $\mathrm{Z}, \mathrm{N} / \mathrm{m}^{2}$

PE perimeter of vapor passage cross section, $m$

PL liquid pressure in wick at position $\mathrm{Z}, \mathrm{N} / \mathrm{m}^{2}$

PORE porosity of wick, volume of void in wick per wick volume

Q axial vapor heat transport at position $\mathrm{Z}, \mathrm{W}$

RADK nondimensional factor including emissivity, view factor, and fin efficiency

RCM effective minimum capillary radius in wick, $m$

RN minimum nucleation radius, $m$

RSS radius of particles in sintered wick, $m$ 
SA specific area, $\mathrm{m}^{2} / \mathrm{m}$

TBOIL temperature drop through evaporator wick, which will result in boiling if DELTCR is exceeded, $\mathrm{K}$

TM mean temperature at axial position $\mathrm{Z}, \mathrm{K}$

TWI wick thickness, $\mathrm{m}$

T1Z temperature of vapor at vapor-liquid interface at axial position $\mathrm{Z}, \mathrm{K}$

T2Z temperature of liquid at vapor-liquid interface at axial position $\mathrm{Z}, \mathrm{K}$

T3Z temperature of inner surface of pipe at axial position $\mathrm{Z}, \mathrm{K}$

T4Z temperature of the outer surface of pipe at axial position $Z, K$

VM mean velocity at axial position $\mathrm{Z}, \mathrm{m} / \mathrm{s}$

$\mathrm{Z}$ axial distance from beginning of pipe, $\mathrm{m}$

The fluid codes are as follows:

$\begin{array}{llcl}1 & \text { lithium } & 9 & \text { acetone } \\ 2 & \text { potassium } & 10 & \text { benzene } \\ 3 & \text { sodium } & 11 & \text { cesium } \\ 4 & \text { water } & 12 & \text { Freon-11 } \\ 5 & \text { ammonia } & 13 & \text { n-heptane } \\ 6 & \text { methanol } & 14 & \text { silver } \\ 7 & \text { mercury } & 15 & \text { toluene } \\ 8 & \text { Dowtherm A } & 16 & \text { m-xylene }\end{array}$

The material codes are as follows:

$\begin{array}{cl}1 & \text { stainless steel } 304 \\ 2 & \text { titanium } \\ 3 & \text { iron } \\ 4 & \text { nickel } \\ 5 & \text { aluminum } \\ 6 & \text { copper } \\ 7 & \text { niobium-1\% zirconium } \\ 8 & \text { tungsten } \\ 9 & \text { Inconel } \\ 10 & \text { molybdenum } \\ 11 & \text { tantalum } \\ 12 & \text { beryllium }\end{array}$


The wick codes are as follows:

$\begin{array}{ll}1 & \text { user input data } \\ 2 & \text { screen wick } \\ 3 & \text { screen wick with arteries } \\ 4 & \text { sintered metal } \\ 5 & \text { sintered metal with arteries } \\ 6 & \text { grooves }\end{array}$




\section{APPENDIX B}

\section{VAPOR FLOW ALGORITHM*}

\section{Analysis}

In the analysis to follow, the appropriate features of Busse's (ref. 16) method will be introduced, and the development will proceed from there. In addition, some major assumptions for the heat pipe sections being considered should be indicated at the outset: Flow is laminar. The ideal-gas law applies to components of the vapor. The equations allow for local chemical equilibrium among species in the vapor. Phase equilibrium occurs only at the liquid-vapor interface, so that liquid droplets are absent in the vapor. Following Busse (ref. 16), no tangential velocity component exists at the wall in mass addition or removal, the radial pressure gradient may be neglected, and the velocity components are zero at the closed ends of the heat pipe. Also, his method of imposing a negligible radial pressure gradient by equating the mean axial pressure gradient over the cross section to the axial pressure gradient along the centerline was used.

Busse (ref. 16) began with the axial axisymmetric Navier-Stokes equation

$$
\frac{\partial p}{\partial z}=-\rho\left(u \frac{\partial v}{\partial r}+v \frac{\partial v}{\partial z}\right)-\frac{\eta}{r} \frac{\partial}{\partial r} r\left(\frac{\partial u}{\partial z}-\frac{\partial v}{\partial r}\right)
$$

where $p$ is pressure, $r$ is radial distance, $u$ is radial velocity, $v$ is axial velocity, $z$ is axial distance, $\eta$ is dynamic viscosity, and $\rho$ is density. Busse integrated the mass conservation equation with respect to $u$, so that this term can be eliminated. This is also done in the present analysis except that density is variable in $z$ and $r$ :

$$
u=-\frac{1}{r \rho} \int_{0}^{r} \frac{\partial}{\partial z}(\rho v) r^{\prime} d r^{\prime}
$$

When equation (2) is combined with equation (1), the following results:

$$
\frac{\partial p}{\partial z}=\frac{1}{r}\left[\frac{\partial v}{\partial r}\left(\int_{0}^{r} \rho \frac{\partial v}{\partial z} r^{\prime} d r^{\prime}+\int_{0}^{r} v \frac{\partial \rho}{\partial z} r^{\prime} d r^{\prime}\right)\right]-\rho v \frac{\partial v}{\partial z}+\frac{\eta}{r} \frac{\partial}{\partial r} r \frac{\partial v}{\partial r}
$$

Here the axial variation of $u$ has been neglected in the viscous term. The assumption is made that the radial variation of density is much less than the radial variation of axial velocity because the latter vanishes at the liquid-vapor interface. On the basis of this assumption, a presently undefined mean density $\rho_{m}$ and its axial derivative are extracted from the integrals, yielding

$$
\frac{\partial p}{\partial z}=\frac{1}{r}\left[\frac{\partial v}{\partial r}\left(\rho_{m} \int_{0}^{r} \frac{\partial v}{\partial z} r^{\prime} d r^{\prime}+\frac{\partial \rho_{m}}{\partial z} \int_{0}^{r} v r^{\prime} d r^{\prime}\right)\right]-\rho v \frac{\partial v}{\partial z}+\frac{\eta}{r} \frac{\partial}{\partial r} r \frac{\partial v}{\partial r}
$$

"This appendix is taken from reference 17, except for the last two paragraphs, which are new. 
The crux of Busse's attack on the incompressible case is the assumption of an approximate velocity profile that satisfies all the boundary conditions. It incorporates a parameter $A(z)$ that may be constant or may vary with position, depending on mass influx boundary conditions. The same profile is employed in this analysis:

$$
v=2 v_{n}\left(1-\frac{r^{2}}{R^{2}}\right)\left[1+A(z)\left(\frac{r^{2}}{R^{2}}-\frac{1}{3}\right)\right]
$$

Here $v_{m}$ is the mean axial velocity and $R$ is the vapor space radius. When $A(z)=0$, equation (5) reduces to the Poiseuille profile. Integrating equation (4) over the cross section of the pipe and manipulating give

$$
\frac{d p_{m}}{d z}=-\frac{4}{3} \frac{d}{d z}\left[\left(1-\frac{A}{6}+\frac{2 A^{2}}{45}\right)\left(v_{m}^{2} \rho_{m}\right)\right]-\frac{8 \eta v_{m}}{R^{2}}\left(1+\frac{2 A}{3}\right)
$$

The mean density is assumed to be related to the pressure and a mean temperature $T_{m}$ by the idealgas law, which yields upon differentiation

$$
\frac{d \ln \rho_{m}}{d z}=\left(\text { GRP) } \frac{d \ln p}{d z}-\left(\text { GRT) } \frac{d \ln T_{m}}{d z}\right.\right.
$$

where

$$
\mathrm{GRP}=1-\frac{\partial \ln R_{8}}{\partial \ln p} \quad \text { and } \quad \text { GRT }=1+\frac{\partial \ln R_{s}}{\partial \ln T_{m}}
$$

and where $R_{g}$, the gas constant, may depend on pressure and temperature if chemical reactions are considered.

Continuity requires that the vapor mass flux $m(z)$ at any cross section equal the product of mean density $\rho_{m}$, the vapor cross-sectional area $A_{v}$, and the mean axial velocity $v_{m}(z)$. From this relationship and equation (7) the axial derivative of $v_{m}$ is found to be

$$
\frac{d \ln v_{m}}{d z}=\frac{d \ln m}{d z}-\frac{d \ln A_{v}}{d z}-(\text { GRP }) \frac{d \ln p}{d z}+(\text { GRT }) \frac{d \ln T_{m}}{d z}
$$

Equations (6) to (8) are combined and the indicated integrations are performed. Dropping the distinction between the mean cross-sectional pressure and the local pressure by Busse's approximation gives

$$
\begin{aligned}
{\left[1-\frac{4 \rho_{m} v_{m}^{2}}{3 p}(\mathrm{~GB})(\mathrm{GRP})\right] \frac{d \ln p}{d z} } & +\left[\frac{4 \rho_{m} v_{m}^{2}}{3 p}(\mathrm{~GB})(\mathrm{GRT})\right] \frac{d \ln T_{m}}{d z}-\frac{4 \rho_{m} v_{m}^{2}}{3 p}(\mathrm{HB}) \frac{d A}{d z} \\
& =-\frac{8 \eta v_{m}}{R^{2} p}\left(1+\frac{2 A}{3}\right)-\frac{8 \rho_{m} v_{m}^{2}}{3 p}(\mathrm{~GB})\left(\frac{d \ln m}{d z}-\frac{d \ln A_{v}}{d z}\right)
\end{aligned}
$$


where

$$
\mathrm{GB}=\left(1-\frac{A}{6}+\frac{2 A^{2}}{45}\right) \quad \text { and } \quad \mathrm{HB}=-\left(\frac{1}{6}-\frac{4 A}{45}\right)
$$

The variation of $A_{v}$ with $z$ is understood to be small.

The mean temperature $T_{m}$ is evaluated by means of an energy integral. Figure 4 shows the control volume through which energy is transported. The energy flows into the boundary are equated with the energy flows out, internal energy and pressure are eliminated by using enthalpy, and the limit $\Delta z \rightarrow 0$ is taken, to give

$$
\int_{0}^{R}\left[\frac{d}{d z} \rho v\left(h+\frac{v^{2}}{2}\right)\right] r d r=\int_{0}^{R} \Phi r d r+q_{R} R-p R u_{R}
$$

where $h$ is the enthalpy of the mixture per unit mass, $q_{R}$ is the energy flux entering the vapor space radially, and $\Phi$ is the viscous dissipation per unit volume. The relation for $u_{R}$, the radial velocity at the vapor-liquid interface, is given by the mass conservation equation in the form

$$
u_{R}=-\frac{1}{R \rho_{R}} \int_{0}^{R} \frac{d}{d z}(\rho v) r d r
$$

The energy influx $q_{R}$ is specified as $-\rho_{R} u_{R}\left(e_{R}+u_{R}^{2} / 2\right)$, where $e_{R}$ is internal energy. The result of combining equations (10) and (11) is

$$
\int_{0}^{R}\left(h+\frac{v^{2}}{2}-H_{R}\right) \frac{d}{d z}(\rho v) r d r+\int_{0}^{R} \rho v \frac{d h}{d z} r d r+\int_{0}^{R} \rho v^{2} \frac{d v}{d z} r d r=\int_{0}^{R} \Phi r d r
$$

The mean value of both the enthalpy and the density can be separately extracted from the integrals if the assumption is again made that the variation of both variables with radius is much less than that of axial velocity. When these mean values have been extracted and terms common to all expressions cancelled, the energy equation becomes

$$
\left(h_{m}-H_{R}\right) \frac{d}{d z} \rho_{m} v_{m}+\frac{1}{R^{2}}\left(\int_{0}^{R} v^{3} r d r\right) \frac{d \rho_{m}}{d z}+\rho_{m} v_{m} \frac{d h_{m}}{d z}+\frac{\rho_{m}}{R^{2}} \int_{0}^{R} \frac{d v^{3}}{d z} r d r=\frac{2}{R^{2}} \int_{0}^{R} \Phi r d r
$$

where

$$
H_{R}=h_{R}+\frac{u_{R}^{2}}{2}
$$

If chemical equilibrium in the vapor must be considered, enthalpy $h_{m}$ becomes a function of both $T_{m}$ and $p$. When its derivative is inserted into equation (13) with equations (7) and (9) and the integrations are performed, the result is 


$$
\begin{aligned}
{\left[\left(\frac{\partial h_{m}}{\partial \ln p}\right)_{r_{m}}-F_{3} v_{m}^{2}(\mathrm{GRP})\right] \frac{d \ln p}{d z} } & +\left[\left(\frac{\partial h_{m}}{\partial \ln T_{m}}\right)_{p}+F_{3} v_{m}^{2}(\mathrm{GRT})\right] \frac{d \ln T_{m}}{d z}+(\mathrm{HAF}) \frac{d A}{d z} \\
& =8 \eta\left[\frac{\left(1+2 A^{2} / 9\right) v_{m}}{\rho_{m} R^{2}}\right]-(\mathrm{HVE})\left(\frac{d \ln m}{d z}-\frac{d \ln A_{v}}{d z}\right)
\end{aligned}
$$

where

$$
\begin{aligned}
F_{3} & =8\left(\frac{1}{4}-\frac{A}{10}+\frac{A^{2}}{30}-\frac{2 A^{3}}{945}\right) \\
\mathrm{HAF} & =-\frac{2}{5}\left(1-\frac{2 A}{3}+\frac{4 A^{2}}{63}\right) \\
\mathrm{HVE} & =h_{m}-H_{R}+\left(\frac{3 F_{3} v_{m}^{2}}{2}\right)
\end{aligned}
$$

An additional equation required to find the three dependent variables $p, A$, and $T_{m}$ comes from Busse's (ref. 16) approximation that the axial gradient of the mean pressure equals the centerline pressure gradient. The latter, from equation (1) for $r=0$ using equations (4) and (5), is

$$
\begin{aligned}
& {\left[1-\frac{4 \rho_{m} v_{m}^{2}}{p}(1-A / 3)^{2}(\mathrm{GRP})\right] \frac{d \ln p}{d z}+\left[\frac{4 \rho_{m} v_{m}^{2}}{p}(1-A / 3)^{2}(\mathrm{GRT})\right] \frac{d \ln T_{m}}{d z}} \\
& \quad-\left[\frac{4 \rho_{m} v_{m}^{2}}{3 p}(1-A / 3)\right] \frac{d A}{d z}=\frac{-8 \eta v_{m}}{p R^{2}}(1-4 A / 3)-\left[\frac{4 \rho_{m} v_{m}^{2}}{p}(1-A / 3)^{2}\right]\left(\frac{d \ln m}{d z}-\frac{d \ln A_{v}}{d z}\right)
\end{aligned}
$$

The mass flux is related to the heat flux into the pipe by

$$
\frac{d q_{R}}{d z}=\frac{1}{2 \pi R} \frac{d m}{d z}\left[h_{v l}+\left(\frac{1}{2 \pi R \rho_{R}} \frac{d m}{d z}\right)^{2}\right]
$$

where the kinetic energy of the injected vapor has been incorporated, and $h_{v l}$ is the heat of evaporation. Equations (9), (14), and (15), with equation (16) and appropriate boundary conditions, enable a solution for $p, A$, and $T_{m}$.

At extremely low Mach numbers the flow approaches the incompressible condition. The solution algorithm defined by the foregoing equations breaks down because of roundoff error in the computer. A simple fix can be devised for the very low peak Mach number regime by returning to the original equations of Busse (ref. 16) derived for incompressible conditions. 
Busse's equations (18) and (20) can be combined to obtain an expression for the change of mean pressure with distance in the following form:

$$
\frac{d p}{d z}=\frac{-\left[\rho v_{m}^{2}\left(180-48 A+4 A^{2}\right) \frac{d \ln v_{m}}{d z}+\frac{8 \eta v_{m}}{R^{2}}\left(75+58 A-\frac{92 A^{2}}{3}\right)\right]}{75-22 A}
$$

In the equation the mean velocity derivative is eliminated by the substitution

$$
\frac{d \ln m}{d z}=\frac{d \ln v_{m}}{d z}+\frac{d \ln A_{v}}{d z}
$$

The change of velocity profile parameter can be expressed as

$$
\frac{d A}{d z}=\frac{\left[\left(90-150 A+22 A^{2}\right) \frac{d \ln v_{m}}{d z}-\frac{1040 \eta A}{R^{2} \rho v_{m}}\right]}{75-22 A}
$$

In the code equations (17) and (18) are solved for each step as though the flow were incompressible. However, the density is updated by means of the gas law. The saturated vapor interface temperature is employed in the gas law. This procedure was used when the highest Mach number at any point in the pipe fell below 0.01 . 


\section{APPENDIX C \\ USER-INTERACTIVE DATA ENTRY FOR FIRST EXAMPLE CASE}

The example case given here demonstrates the flexibility of this code. The heat pipe is made of stainless steel and has sodium as a working fluid. The heat pipe has four different sections: two evaporators, one adiabatic section, and one condenser section. The heat input profiles are known for both evaporators and are shown graphically in figure 5. The heat input is constant for the upstream evaporator but variable for the other evaporator. The heat input is known at three points along the variable evaporator section. The code will solve for the temperature distribution along the heat pipe and the heat load distribution in the condenser section.

The input procedure for the example given here is exactly as it appears on the computer screen.

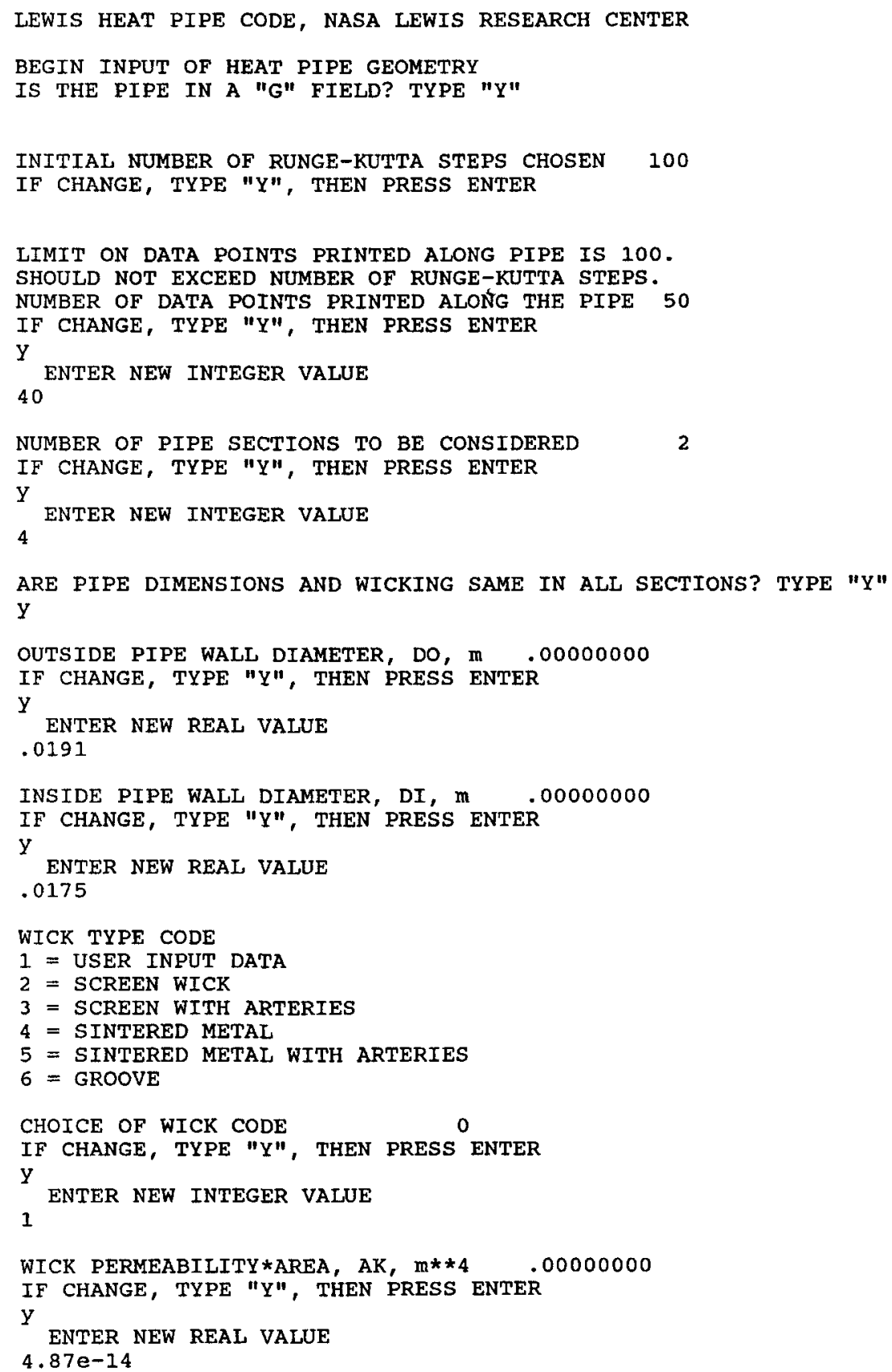




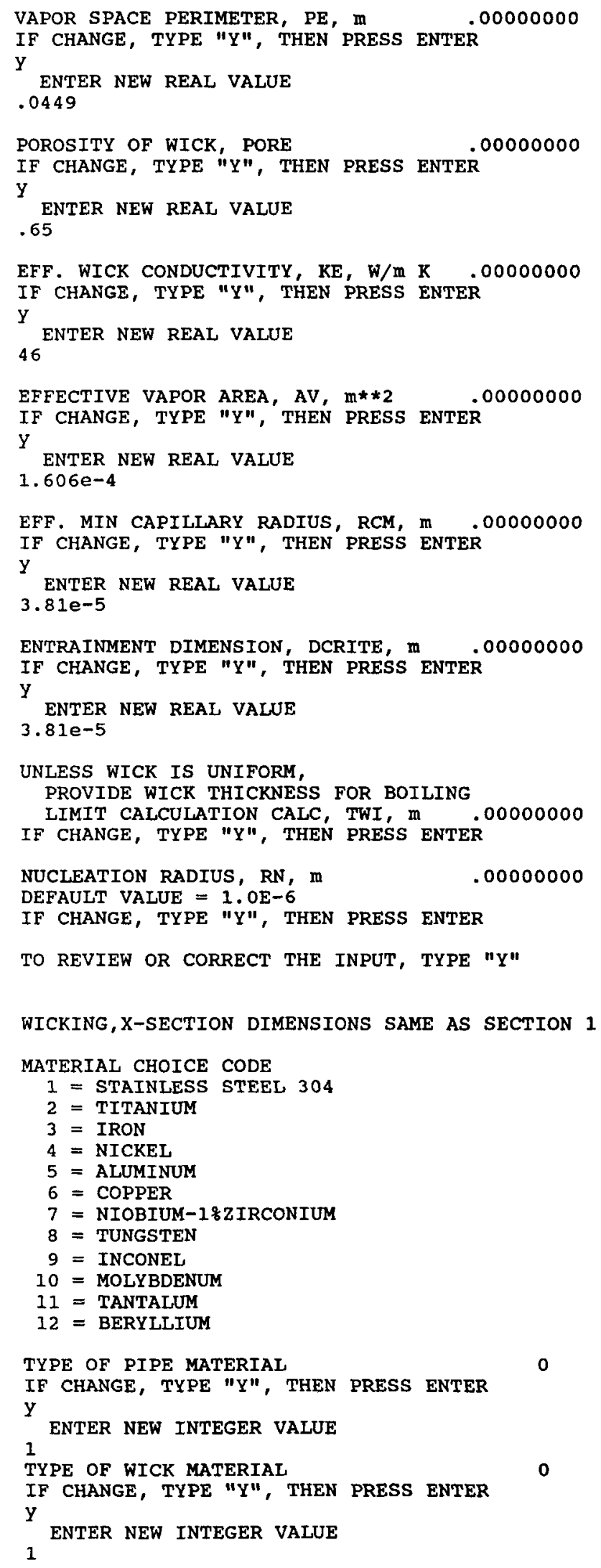

ENTER NEW INTEGER VALUE 


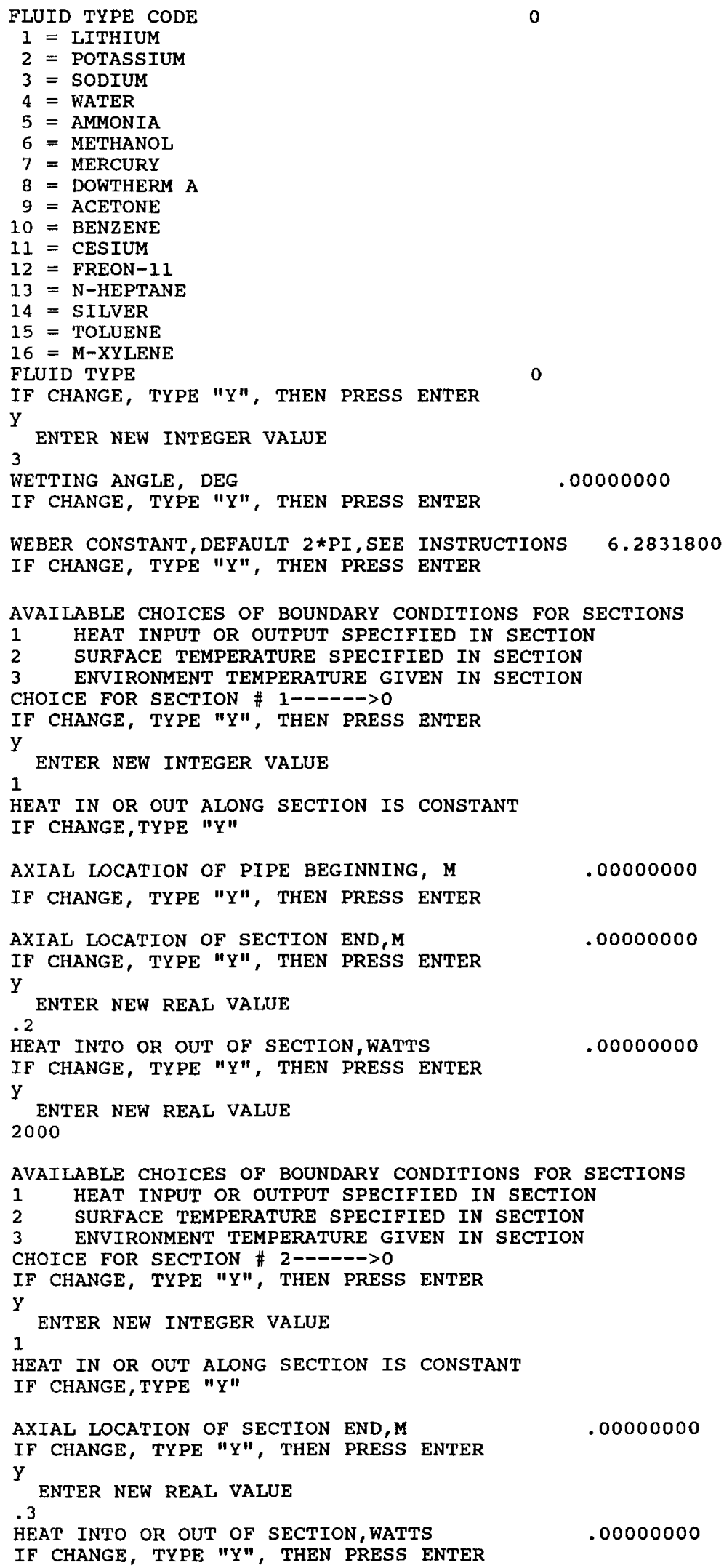




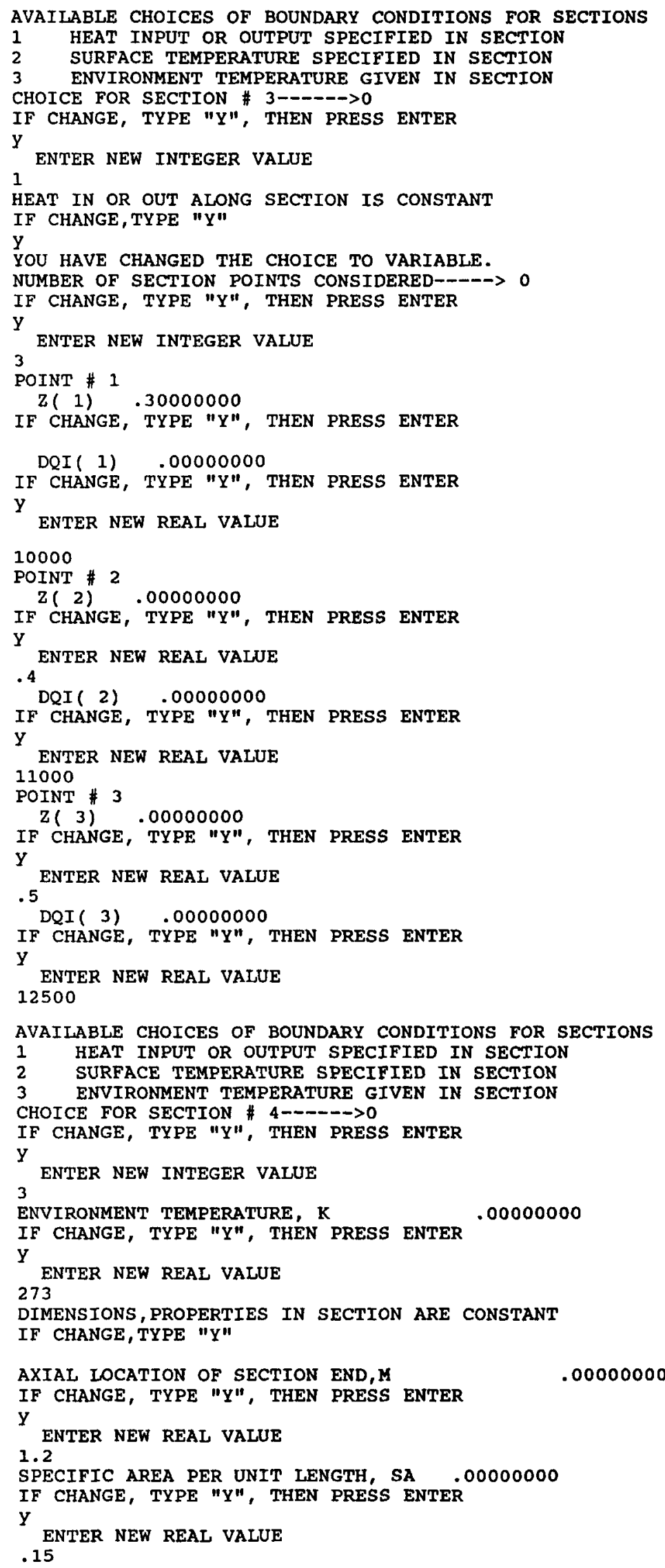




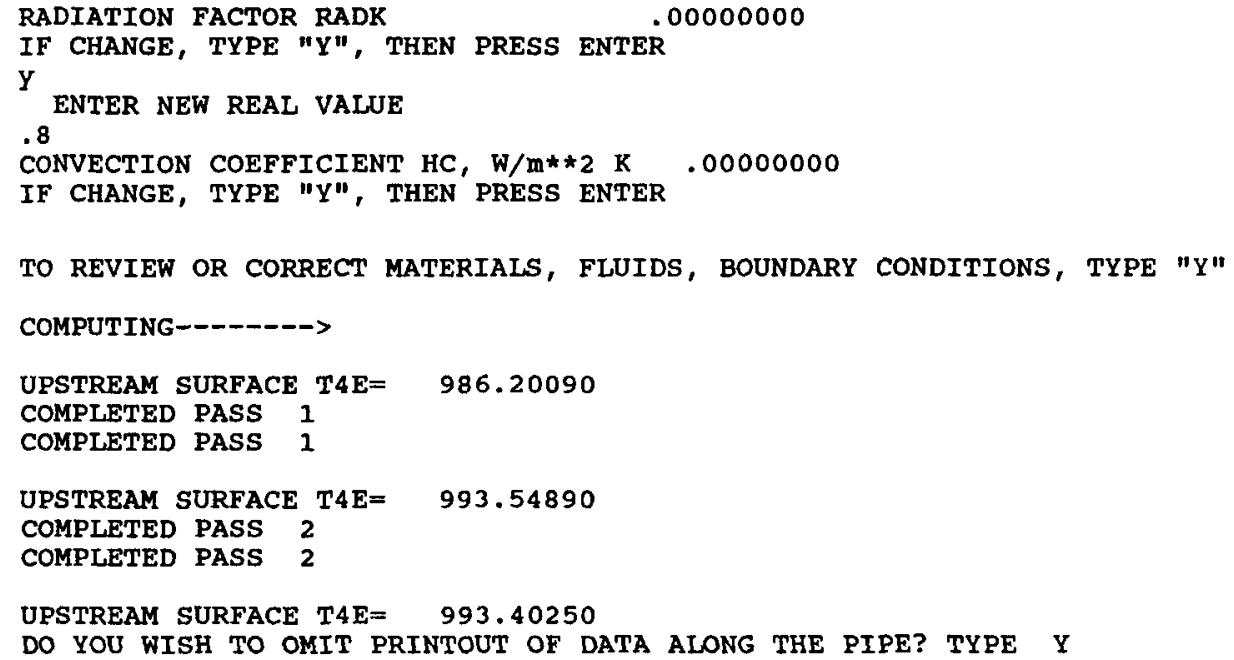




\section{APPENDIX D}

\section{OUTPUT DATA FOR EXAMPLE CASE}

The output data for the example case described in appendix $\mathbf{C}$ are given here. They are presented exactly as they appear by running the code.

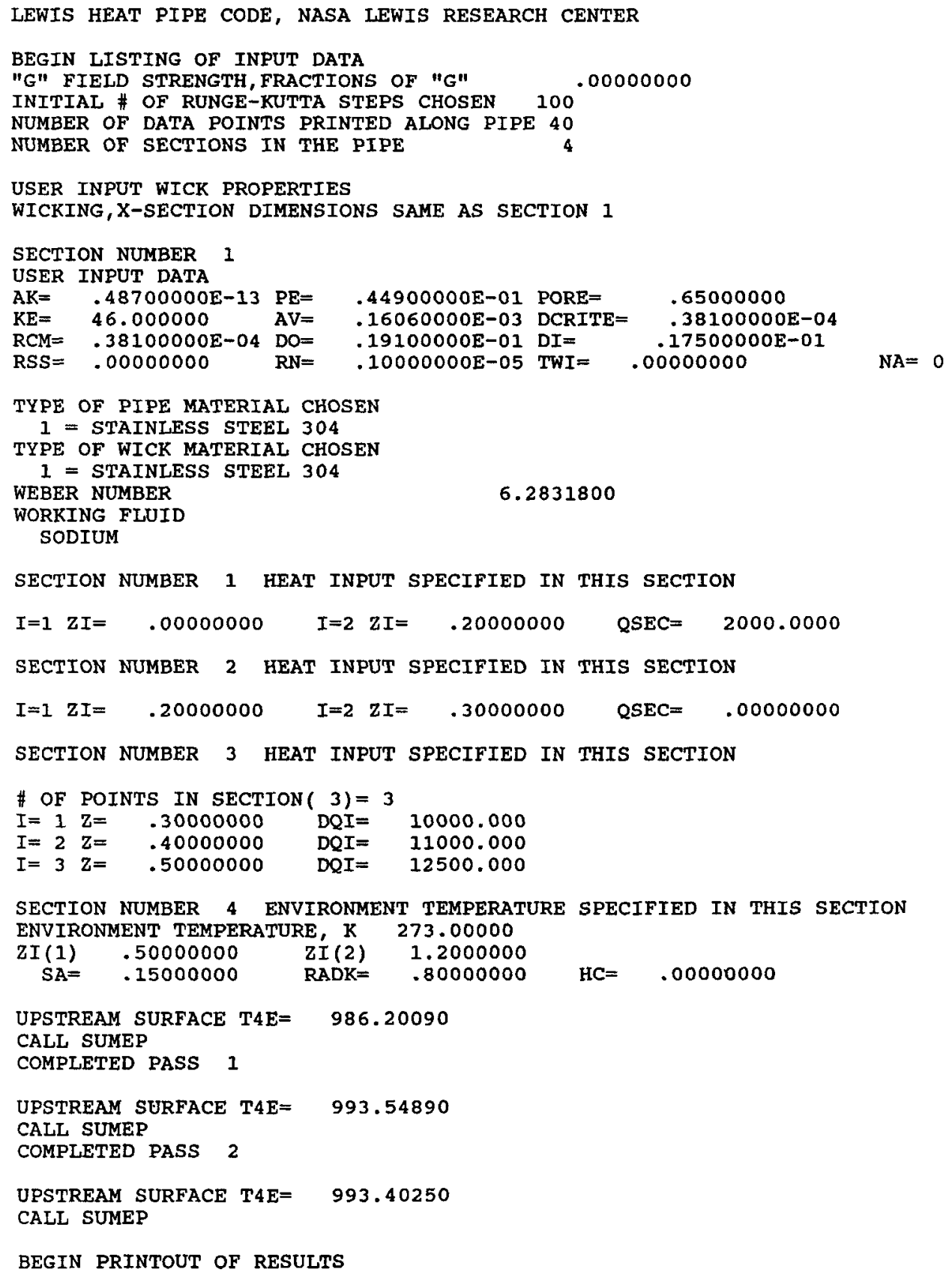


BEGIN SECTION \# 1

MENISCUS PRESS. DIFFERENCE

VAPOR - LIQUID, N/SQ $M=$ CAPILLARY LIMIT, $N / S Q M=$

\begin{tabular}{|c|c|c|c|c|c|}
\hline $\begin{array}{l}\mathrm{Z}= \\
\mathrm{T} 1 \mathrm{Z}= \\
\mathrm{VM}= \\
\mathrm{DQDZ}=\end{array}$ & $\begin{array}{l}.00000000 \\
980.49690 \\
.00000000 \\
10000.000\end{array}$ & $\begin{array}{l}\mathrm{P}= \\
\mathrm{T} 4 \mathrm{Z}= \\
\mathrm{MACHM}= \\
\mathrm{Q}=\end{array}$ & $\begin{array}{l}15478.560 \\
993.40250 \\
.00000000 \\
.00000000\end{array}$ & $\begin{array}{l}\mathrm{PL}= \\
\mathrm{TM}= \\
\mathrm{A}=\end{array}$ & $\begin{array}{l}12075.110 \\
980.49690 \\
.54389510\end{array}$ \\
\hline $\begin{array}{l}\mathrm{Z}= \\
\mathrm{T} 1 \mathrm{Z}= \\
\mathrm{VM}= \\
\mathrm{DQDZ}=\end{array}$ & $\begin{array}{l}.30000000 \mathrm{E}-01 \\
980.47120 \\
9.7012210 \\
10000.000\end{array}$ & $\begin{array}{l}\mathrm{P}= \\
\mathrm{T} 4 \mathrm{Z}= \\
\mathrm{MACHM}= \\
\mathrm{Q}=\end{array}$ & $\begin{array}{l}15473.500 \\
993.37680 \\
15445590 \mathrm{E}-01 \\
300.00000\end{array}$ & $\begin{array}{l}P L= \\
T M= \\
A=\end{array}$ & $\begin{array}{l}12079.590 \\
980.45940 \\
.54396840\end{array}$ \\
\hline $\begin{array}{l}\mathrm{Z}= \\
\mathrm{T} 1 \mathrm{Z}= \\
\mathrm{VM}= \\
\mathrm{DQDZ}=\end{array}$ & $\begin{array}{l}.60000000 E-01 \\
980.38870 \\
19.419230 \\
10000.000\end{array}$ & $\begin{array}{l}\mathrm{P}= \\
\mathrm{T} 4 \mathrm{Z}= \\
\mathrm{MACHM}= \\
\mathrm{Q}=\end{array}$ & $\begin{array}{l}15457.290 \\
993.29430 \\
.30920680 \mathrm{E}-01 \\
600.00000\end{array}$ & $\begin{array}{l}\mathrm{PL}= \\
\mathrm{TM}= \\
\mathrm{A}=\end{array}$ & $\begin{array}{l}12093.930 \\
980.32920 \\
.54494620\end{array}$ \\
\hline $\begin{array}{l}\mathrm{Z}= \\
\mathrm{T} 1 \mathrm{Z}= \\
\mathrm{VM}= \\
\mathrm{DQDZ}=\end{array}$ & $\begin{array}{l}.90000000 \mathrm{E}-01 \\
980.23850 \\
29.176580 \\
10000.000\end{array}$ & $\begin{array}{l}\mathrm{P}= \\
\mathrm{T} 4 \mathrm{Z}= \\
\mathrm{MACHM}= \\
\mathrm{Q}=\end{array}$ & $\begin{array}{l}15427.840 \\
993.14410 \\
.46464980 \mathrm{E}-01 \\
900.00010\end{array}$ & $\begin{array}{l}P L= \\
T M= \\
A=\end{array}$ & $\begin{array}{l}12119.930 \\
980.09250 \\
.54616770\end{array}$ \\
\hline $\begin{array}{l}Z= \\
T 1 Z= \\
V M= \\
D Q D Z=\end{array}$ & $\begin{array}{l}.12000000 \\
980.02490 \\
38.990310 \\
10000.000\end{array}$ & $\begin{array}{l}\mathrm{P}= \\
\mathrm{T} 4 \mathrm{Z}= \\
\mathrm{MACHM}= \\
\mathrm{Q}=\end{array}$ & $\begin{array}{l}15386.060 \\
992.93050 \\
.62108500 \mathrm{E}-01 \\
1200.0000\end{array}$ & $\begin{array}{l}P L= \\
T M= \\
A=\end{array}$ & $\begin{array}{l}12156.700 \\
979.75580 \\
.54788410\end{array}$ \\
\hline $\begin{array}{l}Z= \\
T 1 Z= \\
V M= \\
D Q D Z=\end{array}$ & $\begin{array}{l}.15000000 \\
979.74160 \\
48.887650 \\
10000.000\end{array}$ & $\begin{array}{l}\mathrm{P}= \\
\mathrm{T} 4 \mathrm{Z}= \\
\mathrm{MACHM}= \\
\mathrm{Q}=\end{array}$ & $\begin{array}{l}15330.770 \\
992.64730 \\
.77899230 \mathrm{E}-01 \\
1500.0000\end{array}$ & $\begin{array}{l}P L= \\
T M= \\
A=\end{array}$ & $\begin{array}{l}12205.140 \\
979.30830 \\
.55014200\end{array}$ \\
\hline $\begin{array}{l}\mathrm{Z}= \\
\mathrm{T} 1 \mathrm{Z}= \\
\mathrm{VM}= \\
\mathrm{DQDZ}=\end{array}$ & $\begin{array}{l}.18000000 \\
979.39230 \\
58.884090 \\
10000.000\end{array}$ & $\begin{array}{l}\mathrm{P}= \\
\mathrm{T} 4 \mathrm{Z}= \\
\mathrm{MACHM}= \\
\mathrm{Q}=\end{array}$ & $\begin{array}{l}15262.800 \\
992.29800 \\
.93864520 \mathrm{E}-01 \\
1800.0000\end{array}$ & $\begin{array}{l}\mathrm{PL}= \\
\mathrm{TM}= \\
\mathrm{A}=\end{array}$ & $\begin{array}{l}12264.360 \\
978.75700 \\
.55291210\end{array}$ \\
\hline $\begin{array}{l}Z= \\
T 1 Z= \\
V M= \\
D Q D Z=\end{array}$ & $\begin{array}{l}.20000000 \\
979.11790 \\
65.619220 \\
10000.000\end{array}$ & $\begin{array}{l}\mathrm{P}= \\
\mathrm{T} 4 \mathrm{Z}= \\
\mathrm{MACHM}= \\
\mathrm{Q}=\end{array}$ & $\begin{array}{l}15209.590 \\
992.02350 \\
.10463320 \\
1999.9810\end{array}$ & $\begin{array}{l}P L= \\
T M= \\
A=\end{array}$ & $\begin{array}{l}12310.440 \\
978.32260 \\
.55507700\end{array}$ \\
\hline
\end{tabular}

BEGIN SECTION \# 2

MENISCUS PRESS. DIFFERENCE

VAPOR - LIQUID, N/SQ $M=$ CAPILILARY LIMIT, N/SQ $M=$

\begin{tabular}{|c|c|c|c|c|c|}
\hline $\begin{array}{l}\mathrm{Z}= \\
\mathrm{T} 1 \mathrm{Z}= \\
\mathrm{VM}= \\
\mathrm{DQDZ}=\end{array}$ & $\begin{array}{l}.20000000 \\
979.11790 \\
65.619220 \\
.00000000\end{array}$ & $\begin{array}{l}\mathrm{P}= \\
\mathrm{T} 4 \mathrm{Z}= \\
\mathrm{MACHM}= \\
\mathrm{Q}=\end{array}$ & $\begin{array}{l}15209.590 \\
979.11790 \\
.10463320 \\
1999.9810\end{array}$ & $\begin{array}{l}\mathrm{PL}= \\
\mathrm{TM}= \\
\mathrm{A}=\end{array}$ & $\begin{array}{l}12310.440 \\
978.32260 \\
.55507700\end{array}$ \\
\hline $\begin{array}{l}\mathrm{Z}= \\
\mathrm{T} 1 \mathrm{Z}= \\
\mathrm{VM}= \\
\mathrm{DQDZ}=\end{array}$ & $\begin{array}{l}.21000000 \\
979.10060 \\
65.633900 \\
.00000000\end{array}$ & $\begin{array}{l}\mathrm{P}= \\
\mathrm{T} 4 \mathrm{Z}= \\
\mathrm{MACHM}= \\
\mathrm{Q}=\end{array}$ & $\begin{array}{l}15206.260 \\
979.10060 \\
.10465630 \\
1999.9810\end{array}$ & $\begin{array}{l}\mathrm{PL}= \\
\mathrm{TM}= \\
\mathrm{A}=\end{array}$ & $\begin{array}{l}12335.370 \\
978.31480 \\
.54332270\end{array}$ \\
\hline $\begin{array}{l}Z= \\
T 1 Z= \\
V M= \\
D Q D Z=\end{array}$ & $\begin{array}{l}24000000 \\
979.04960 \\
65.677570 \\
.00000000\end{array}$ & $\begin{array}{l}\mathrm{P}= \\
\mathrm{T} 4 \mathrm{Z}= \\
\mathrm{MACHM}= \\
\mathrm{Q}=\end{array}$ & $\begin{array}{l}15196.370 \\
979.04960 \\
110472470 \\
1999.9810\end{array}$ & $\begin{array}{l}\mathrm{PL}= \\
\mathrm{TM}= \\
\mathrm{A}=\end{array}$ & $\begin{array}{l}12410.190 \\
978.29270 \\
.50979230\end{array}$ \\
\hline $\begin{array}{l}Z= \\
T I Z= \\
V M= \\
D Q D Z=\end{array}$ & $\begin{array}{l}.27000000 \\
978.99930 \\
65.720570 \\
.00000000\end{array}$ & $\begin{array}{l}\mathrm{P}= \\
\mathrm{T} 4 \mathrm{Z}= \\
\mathrm{MACHM}= \\
\mathrm{Q}=\end{array}$ & $\begin{array}{l}15186.670 \\
978.99930 \\
.10479190 \\
1999.9810\end{array}$ & $\begin{array}{l}P L= \\
T M= \\
A=\end{array}$ & $\begin{array}{l}12485.010 \\
978.27170 \\
.47874090\end{array}$ \\
\hline $\begin{array}{l}\mathrm{Z}= \\
\mathrm{T} 1 \mathrm{Z}= \\
\mathrm{VM}=\end{array}$ & $\begin{array}{l}.30000000 \\
978.95030 \\
65.762900\end{array}$ & $\begin{array}{l}\mathrm{P}= \\
\mathrm{T} 4 \mathrm{Z}= \\
\mathrm{MACHM}=\end{array}$ & $\begin{array}{l}15177.170 \\
978.95030 \\
.10485800\end{array}$ & $\begin{array}{l}\mathrm{PL}= \\
\mathrm{TM}= \\
\mathrm{A}=\end{array}$ & $\begin{array}{r}12559.830 \\
978.25260 \\
.44999400\end{array}$ \\
\hline
\end{tabular}


BEGIN SECTION \# 3

MENISCUS PRESS. DIFFERENCE

VAPOR - LIQUID, N/SQ M = CAPILLARY LIMIT, $N / S Q M=$

2617.3410

6871.4060

$\mathrm{T} 1 \mathrm{Z}=\quad \mathbf{9 7 8 . 9 5 0 3 0}$

$\mathrm{VM}=\quad 65.762900$

$\mathrm{DQDZ}=10000.000$

$Z=\quad .33000000$

$\mathrm{T} 1 \mathrm{Z}=\quad 978.47800$

$\mathrm{VM}=\quad 76.042410$

$\mathrm{DQDZ}=10101.520$

$\mathrm{Z}=\quad .36000000$

$\mathrm{T} 1 \mathrm{Z}=\quad 977.92240$

$\mathrm{VM}=\quad 86.671330$

$\mathrm{DQDZ}=10378.000$

$\mathrm{Z}=\quad .39000000$

$\mathrm{T} 1 \mathrm{Z}=\quad 977.25820$

$\mathrm{VM}=\quad 97.914080$

$\mathrm{DQDZ}=10822.960$

$Z=\quad .42000000$

$\mathrm{T} 1 \mathrm{Z}=\quad 976.47110$

$\mathrm{VM}=\quad 109.94350$

$\mathrm{DQDZ}=11396.000$

$z=\quad .45000000$

$\mathrm{T} 12=\quad 975.52310$

$\mathrm{VM}=\quad 123.02390$

$\mathrm{DQDZ}=11981.000$

$\mathrm{Z}=\quad .48000000$

$\mathrm{T} 1 \mathrm{Z}=\quad 974.40520$

$\mathrm{VM}=\quad 137.12450$

$\mathrm{DQDZ}=12404.000$

$\mathrm{z}=$

$\mathrm{T} 1 \mathrm{Z}=$

.50000000

973.55330

M= $\quad 147.07040$

$D Q D Z=$

12500.000

$\mathrm{P}=$

$\mathrm{T} 4 \mathrm{Z}=$

MACHM=

$Q=$

$\mathrm{P}=$

$\mathrm{T} 4 \mathrm{Z}=$

$\mathrm{MACHM}=$

$\mathrm{Q}=$

$\mathrm{P}=$

$\mathrm{T} 4 \mathrm{Z}=$

$\mathrm{MACHM}=$

$\mathrm{Q}=$

$\mathrm{P}=$

T4Z=

MACHM=

$Q=$

$\mathrm{P}=$

$\mathrm{T} 4 \mathrm{Z}=$

MACHM=

$Q=$

$\mathrm{P}=$

$\mathrm{T} 4 \mathrm{Z}=$

$\mathrm{Q}=$

$\mathrm{P}=$

$\mathrm{T} 4 \mathrm{Z}=$

MACHM=

$Q=$

$\mathrm{P}=$

$\mathrm{T} 4 \mathrm{Z}=$

MACHM=

$Q=$
BEGIN SECTION \# 4

MENISCUS PRESS. DIFFERENCE

VAPOR - IIQUID, $N / S Q M=$ CAPILLARY LIMIT, N/SQ $M=$

\begin{tabular}{|c|c|}
\hline $\begin{array}{l}Z= \\
\Gamma 1 Z= \\
V M= \\
D Q D Z=\end{array}$ & $\begin{array}{r}500000 \\
973.553 \\
147.070 \\
-5945.06\end{array}$ \\
\hline $\begin{array}{l}= \\
1 \mathrm{Z}= \\
\mathrm{M}= \\
\mathrm{QDZ}=\end{array}$ & $\begin{array}{r}.510000 \\
973.70 \\
144.78 \\
-5947.4\end{array}$ \\
\hline $\begin{array}{l}\mathrm{Z}= \\
\mathrm{T} 1 \mathrm{Z}= \\
\mathrm{VM}= \\
\mathrm{DQDZ}=\end{array}$ & $\begin{array}{r}54000 \\
974.14 \\
137.97 \\
-5957.7\end{array}$ \\
\hline $\begin{array}{l}Z= \\
T 12= \\
V M= \\
D Q D Z=\end{array}$ & $\begin{array}{r}.570000 \\
974.560 \\
131.247 \\
-5967.84\end{array}$ \\
\hline $\begin{array}{l}Z= \\
\mathrm{T} 1 \mathrm{Z}= \\
\mathrm{VM}=\end{array}$ & 977.4 \\
\hline
\end{tabular}

$\mathrm{P}=$

$\mathrm{T} 4 \mathrm{Z}=$

MACHM=

$Q=$

$\mathrm{P}=$

$\mathrm{T} 4 \mathrm{Z}=$

MACHM=

$Q=$

$\mathrm{P}=$

$\mathrm{T} 4 \mathrm{Z}=$

$\mathrm{MACHM}=$

$Q=$

$\mathrm{P}=$

$\mathrm{T} 4 \mathrm{Z}=$

MACHM=

$\mathrm{Q}=$

$P=$

$\mathrm{T} 4 \mathrm{Z}=$

$\mathrm{MACHM}=$

$Q=$
15177.170

991.86660

.10485800

1999.9810

15086.210

991.52550

.12131640

2300.9140

14979.850

991.32700

.13836290

2607.0600

14853.530

991.23760

.15643310

2924.2500

14704.910

991.19060

17581380

3256.0190

14527.450

990.99820

.19695300

3606.3140

14320.230

990.42670

.21981850

3971.8080

14163.720

989.69870

23600390

4220.9930

854.52640

6871.4060

14163.670

965.82340

.23600390

4220.9930

14191.280

965.97160

.23227340

4161.5360

14271.620

966.39680

.22118110

3982.9570

14348.350

966.80070

.21023160

3804.0720

14421.420

967.18370

.19941940

3624.8870
$\mathrm{PL}=\quad 12559.830$

$\mathrm{TM}=\quad 978.25260$

$A=\quad .44999400$

$\mathrm{PL}=\quad 12638.270$

$\mathrm{TM}=\quad 977.48750$

$\mathrm{A}=\quad .48685010$

$\mathrm{PL}=\quad 12727.610$

$\mathrm{TM}=\quad 976.59390$

$\mathrm{A}=\quad .51268230$

$\mathrm{PL}=\quad 12829.080$

$\mathrm{TM}=\quad 975.52530$

$A=\quad .53274700$

$\mathrm{PL}=\quad 12942.190$

TM $=\quad 974.25710$

$A=\quad .55040510$

$\mathrm{PL}=\quad 13068.600$

$\mathrm{TM}=\quad 972.72350$

$\mathrm{A}=\quad .56707200$

$\mathrm{PL}=\quad 13207.990$

$\mathrm{TM}=\quad 970.90880$

$\mathrm{A}=\quad .58344870$

$\mathrm{PL}=\quad 13309.140$

$\mathrm{TM}=\quad 969.51760$

$\mathrm{A}=\quad .59423330$

$\mathrm{PL}=\quad 13309.140$

$\mathrm{TM}=\quad 969.51760$

$A=\quad .59423330$

$\mathrm{PL}=\quad 13362.120$

$\mathrm{TM}=\quad 969.83670$

$\mathrm{A}=\quad .58383650$

$\mathrm{PL}=\quad 13516.680$

$T M=\quad 970.76740$

$\mathrm{A}=\quad .55109640$

$\mathrm{PL}=\quad 13664.510$

$T M=\quad 971.65890$

$\mathrm{A}=\quad .51570630$

$\mathrm{PL}=\quad 13805.420$

$\mathrm{TM}=\quad 972.51320$

$A=\quad .47716730$ 


\begin{tabular}{|c|c|c|c|c|c|}
\hline $\begin{array}{l}\mathrm{Z}= \\
\mathrm{T} 1 \mathrm{Z}= \\
\mathrm{VM}= \\
\mathrm{DQDZ}=\end{array}$ & $\begin{array}{r}.63000000 \\
975.33080 \\
117.99240 \\
-5986.5470\end{array}$ & $\begin{array}{l}\mathrm{P}= \\
\text { T4Z= } \\
\mathrm{MACHM}= \\
\mathrm{Q}=\end{array}$ & $\begin{array}{l}14491.000 \\
967.54690 \\
.18873140 \\
3445.4260\end{array}$ & $\begin{array}{l}\mathrm{PL}= \\
\mathrm{TM}= \\
\mathrm{A}=\end{array}$ & $\begin{array}{l}13939.610 \\
973.33220 \\
.43506880\end{array}$ \\
\hline $\begin{array}{l}\mathrm{Z}= \\
\mathrm{T} 1 \mathrm{Z}= \\
\mathrm{VM}= \\
\mathrm{DQDZ}=\end{array}$ & $\begin{array}{r}.66000000 \\
975.68550 \\
111.45940 \\
-5995.1740\end{array}$ & $\begin{array}{l}\mathrm{P}= \\
\mathrm{T} 4 \mathrm{Z}= \\
\mathrm{MACHM}= \\
\mathrm{Q}=\end{array}$ & $\begin{array}{l}14557.100 \\
967.89040 \\
.17816200 \\
3265.6950\end{array}$ & $\begin{array}{l}\mathrm{PL}= \\
\mathrm{TM}= \\
\mathrm{A}=\end{array}$ & $\begin{array}{l}14066.880 \\
974.11910 \\
.38868870\end{array}$ \\
\hline $\begin{array}{l}\mathrm{Z}= \\
\mathrm{T} 1 \mathrm{Z}= \\
\mathrm{VM}= \\
\mathrm{DQDZ}=\end{array}$ & $\begin{array}{r}69000010 \\
976.02110 \\
104.98300 \\
-6003.3400\end{array}$ & $\begin{array}{l}\mathrm{P}= \\
\mathrm{T} 4 \mathrm{Z}= \\
\mathrm{MACHM}= \\
\mathrm{Q}=\end{array}$ & $\begin{array}{l}14619.830 \\
968.21530 \\
.16770040 \\
3085.7160\end{array}$ & $\begin{array}{l}\mathrm{PL}= \\
\mathrm{TM}= \\
\mathrm{A}=\end{array}$ & $\begin{array}{r}14187.420 \\
974.87700 \\
.33740190\end{array}$ \\
\hline $\begin{array}{l}\mathrm{Z}= \\
\mathrm{T} 1 \mathrm{Z}= \\
\mathrm{VM}= \\
\mathrm{DQDZ}=\end{array}$ & $\begin{array}{r}.72000000 \\
976.33720 \\
98.560410 \\
-6011.0470\end{array}$ & $\begin{array}{l}\mathrm{P}= \\
\mathrm{T} 4 \mathrm{Z}= \\
\mathrm{MACHM}= \\
\mathrm{Q}=\end{array}$ & $\begin{array}{l}14679.150 \\
968.52150 \\
.15734140 \\
2905.4960\end{array}$ & $\begin{array}{l}\mathrm{PL}= \\
\mathbf{T M}= \\
\mathbf{A}=\end{array}$ & $\begin{array}{r}14301.050 \\
975.60780 \\
.28011890\end{array}$ \\
\hline $\begin{array}{l}\mathrm{Z}= \\
\mathrm{T} 1 \mathrm{Z}= \\
\mathrm{VM}= \\
\mathrm{DQDZ}=\end{array}$ & $\begin{array}{r}.75000000 \\
976.63500 \\
92.186580 \\
-6018.3130\end{array}$ & $\begin{array}{l}\mathrm{P}= \\
\mathrm{T} 4 \mathrm{Z}= \\
\mathrm{MACHM}= \\
\mathrm{Q}=\end{array}$ & $\begin{array}{l}14735.200 \\
968.80980 \\
.14707530 \\
2725.0550\end{array}$ & $\begin{array}{l}P L= \\
T M= \\
\mathbf{A}=\end{array}$ & $\begin{array}{l}14407.960 \\
976.31530 \\
.21584330\end{array}$ \\
\hline $\begin{array}{l}\mathrm{Z}= \\
\mathrm{T} 1 \mathrm{Z}= \\
\mathrm{VM}= \\
\mathrm{DQDZ}=\end{array}$ & $\begin{array}{r}.78000000 \\
976.91440 \\
85.848580 \\
-6025.1390\end{array}$ & $\begin{array}{l}\mathrm{P}= \\
\mathrm{T} 4 \mathrm{Z}= \\
\mathrm{MACHM}= \\
\mathrm{Q}=\end{array}$ & $\begin{array}{l}14787.960 \\
969.08030 \\
.13689080 \\
2544.3990\end{array}$ & $\begin{array}{l}\mathrm{PL}= \\
\mathrm{TM}= \\
\mathrm{A}=\end{array}$ & $\begin{array}{l}14507.970 \\
976.93710 \\
.14261760\end{array}$ \\
\hline $\begin{array}{l}\mathrm{Z}= \\
\mathrm{TIZ}= \\
\mathrm{VM}= \\
\mathrm{DQDZ}=\end{array}$ & $\begin{array}{r}.81000010 \\
977.17710 \\
79.497240 \\
-6031.5630\end{array}$ & $\begin{array}{l}\mathrm{P}= \\
\mathrm{T} 4 \mathrm{Z}= \\
\mathrm{MACHM}= \\
\mathrm{Q}=\end{array}$ & $\begin{array}{l}14837.720 \\
969.33470 \\
.12675310 \\
2363.5470\end{array}$ & $\begin{array}{l}\mathrm{PL}= \\
\mathrm{TM}= \\
\mathrm{A}=\end{array}$ & $\begin{array}{l}14601.270 \\
977.17710 \\
.57391190 \mathrm{E}-01\end{array}$ \\
\hline $\begin{array}{l}\mathrm{Z}= \\
\mathrm{T} 1 \mathrm{Z}= \\
\mathrm{VM}= \\
\mathrm{DQDZ}=\end{array}$ & $\begin{array}{r}.84000000 \\
977.42190 \\
73.198290 \\
-6037.5610\end{array}$ & $\begin{array}{l}\mathrm{P}= \\
\mathrm{T} 4 \mathrm{Z}= \\
\mathrm{MACHM}= \\
\mathrm{Q}=\end{array}$ & $\begin{array}{l}14884.210 \\
969.57180 \\
.11669880 \\
2182.5070\end{array}$ & $\begin{array}{l}\mathrm{PL}= \\
\mathrm{TM}= \\
\mathrm{A}=\end{array}$ & $\begin{array}{c}14687.690 \\
977.42190 \\
-.41471180 \mathrm{E}-01\end{array}$ \\
\hline $\begin{array}{l}\mathrm{Z}= \\
\mathrm{T} \perp \mathrm{Z}= \\
\mathrm{VM}= \\
\mathrm{DQDZ}=\end{array}$ & $\begin{array}{r}.87000000 \\
977.64960 \\
66.942950 \\
-6043.1420\end{array}$ & $\begin{array}{l}\mathrm{P}= \\
\mathrm{T} 4 \mathrm{Z}= \\
\mathrm{MACHM}= \\
\mathrm{Q}=\end{array}$ & $\begin{array}{l}14927.530 \\
969.79220 \\
.10671660 \\
2001.2950\end{array}$ & $\begin{array}{l}\mathrm{PI}= \\
\mathrm{TM}= \\
\mathrm{A}=\end{array}$ & $\begin{array}{r}14767.410 \\
977.64960 \\
-.15713710\end{array}$ \\
\hline $\begin{array}{l}\mathrm{Z}= \\
\mathrm{T} 1 \mathrm{Z}= \\
\mathrm{VM}= \\
\mathrm{DQDZ}=\end{array}$ & $\begin{array}{r}.90000000 \\
977.85970 \\
60.728450 \\
-6048.3020\end{array}$ & $\begin{array}{l}\mathrm{P}= \\
\mathrm{T} 4 \mathrm{Z}= \\
\mathrm{MACHM}= \\
\mathrm{Q}=\end{array}$ & $\begin{array}{l}14967.640 \\
969.99550 \\
.96802010 \mathrm{E}-01 \\
1819.9200\end{array}$ & $\begin{array}{l}\mathrm{PI}= \\
\mathrm{TM}= \\
\mathrm{A}=\end{array}$ & $\begin{array}{r}14840.250 \\
977.85970 \\
-.29517060\end{array}$ \\
\hline $\begin{array}{l}\mathrm{Z}= \\
\mathrm{T} 1 \mathrm{Z}= \\
\mathrm{VM}= \\
\mathrm{D} Q \mathrm{DZ}=\end{array}$ & $\begin{array}{r}.93000010 \\
978.05330 \\
54.550160 \\
-6053.0600\end{array}$ & $\begin{array}{l}\mathrm{P}= \\
\mathrm{T} 4 \mathrm{Z}= \\
\mathrm{MACHM}= \\
\mathrm{Q}=\end{array}$ & $\begin{array}{l}15004.640 \\
970.18290 \\
.86947200 \mathrm{E}-01 \\
1638.3990\end{array}$ & $\begin{array}{l}P L= \\
T M= \\
A=\end{array}$ & $\begin{array}{r}14906.380 \\
978.05330 \\
-.46195930\end{array}$ \\
\hline $\begin{array}{l}\mathrm{Z}= \\
\mathrm{T} 1 \mathrm{Z}= \\
\mathrm{VM}= \\
\mathrm{DQDZ}=\end{array}$ & $\begin{array}{r}.96000000 \\
978.22980 \\
48.405420 \\
-6057.4070\end{array}$ & $\begin{array}{l}\mathrm{P}= \\
\mathrm{T} 4 \mathrm{Z}= \\
\mathrm{MACHM}= \\
\mathrm{Q}=\end{array}$ & $\begin{array}{l}15038.470 \\
970.35380 \\
.77147890 \mathrm{E}-01 \\
1456.7390\end{array}$ & $\begin{array}{l}\mathrm{PL}= \\
\mathrm{TM}= \\
\mathrm{A}=\end{array}$ & $\begin{array}{r}14965.620 \\
978.22980 \\
-.66906720\end{array}$ \\
\hline $\begin{array}{l}\mathrm{Z}= \\
\mathrm{T} 1 \mathrm{Z}= \\
\mathrm{VM}= \\
\mathrm{DQDZ}=\end{array}$ & $\begin{array}{r}.99000000 \\
978.39010 \\
42.289910 \\
-6061.3610\end{array}$ & $\begin{array}{l}\mathrm{P}= \\
\mathrm{T} 4 \mathrm{Z}= \\
\mathrm{MACHM}= \\
\mathrm{Q}=\end{array}$ & $\begin{array}{l}15069.240 \\
970.50890 \\
.67396930 \mathrm{E}-01 \\
1274.9560\end{array}$ & $\begin{array}{l}\mathrm{PL}= \\
\mathrm{TM}= \\
\mathrm{A}=\end{array}$ & $\begin{array}{r}15018.150 \\
978.39010 \\
-.93133480\end{array}$ \\
\hline $\begin{array}{l}\mathrm{Z}= \\
\mathrm{T} 1 \mathrm{Z}= \\
\mathrm{VM}= \\
\mathrm{DQDZ}=\end{array}$ & $\begin{array}{r}1.0200000 \\
978.53380 \\
36.201170 \\
-6064.9130\end{array}$ & $\begin{array}{l}\mathrm{P}= \\
\mathrm{T} 4 \mathrm{Z}= \\
\mathrm{MACHM}= \\
\mathrm{Q}=\end{array}$ & $\begin{array}{l}15096.870 \\
970.64800 \\
.57690200 \mathrm{E}-01 \\
1093.0600\end{array}$ & $\begin{array}{l}\mathrm{PL}= \\
\mathrm{TM}= \\
\mathrm{A}=\end{array}$ & $\begin{array}{r}15063.790 \\
978.53380 \\
-1.2773560\end{array}$ \\
\hline $\begin{array}{l}\mathrm{Z}= \\
\mathrm{T} 1 \mathrm{Z}= \\
\mathrm{VM}= \\
\mathrm{DQDZ}= \\
\text { REVERSE }\end{array}$ & $\begin{array}{c}1.0500000 \\
978.66160 \\
30.135310 \\
-6068.0740 \\
\text { E VAPOR FLOW }\end{array}$ & $\begin{array}{l}\mathrm{P}= \\
\mathrm{T} 4 \mathrm{Z}= \\
\mathrm{MACHM}= \\
\mathrm{Q}= \\
\text { CONDENS }\end{array}$ & $\begin{array}{l}15121.470 \\
970.77170 \\
.48021260 \mathrm{E}-01 \\
911.06570 \\
\end{array}$ & $\begin{array}{l}\mathrm{PL}= \\
\mathrm{TM}= \\
\mathrm{A}=\end{array}$ & $\begin{array}{r}15102.710 \\
978.66160 \\
-1.7500160\end{array}$ \\
\hline
\end{tabular}




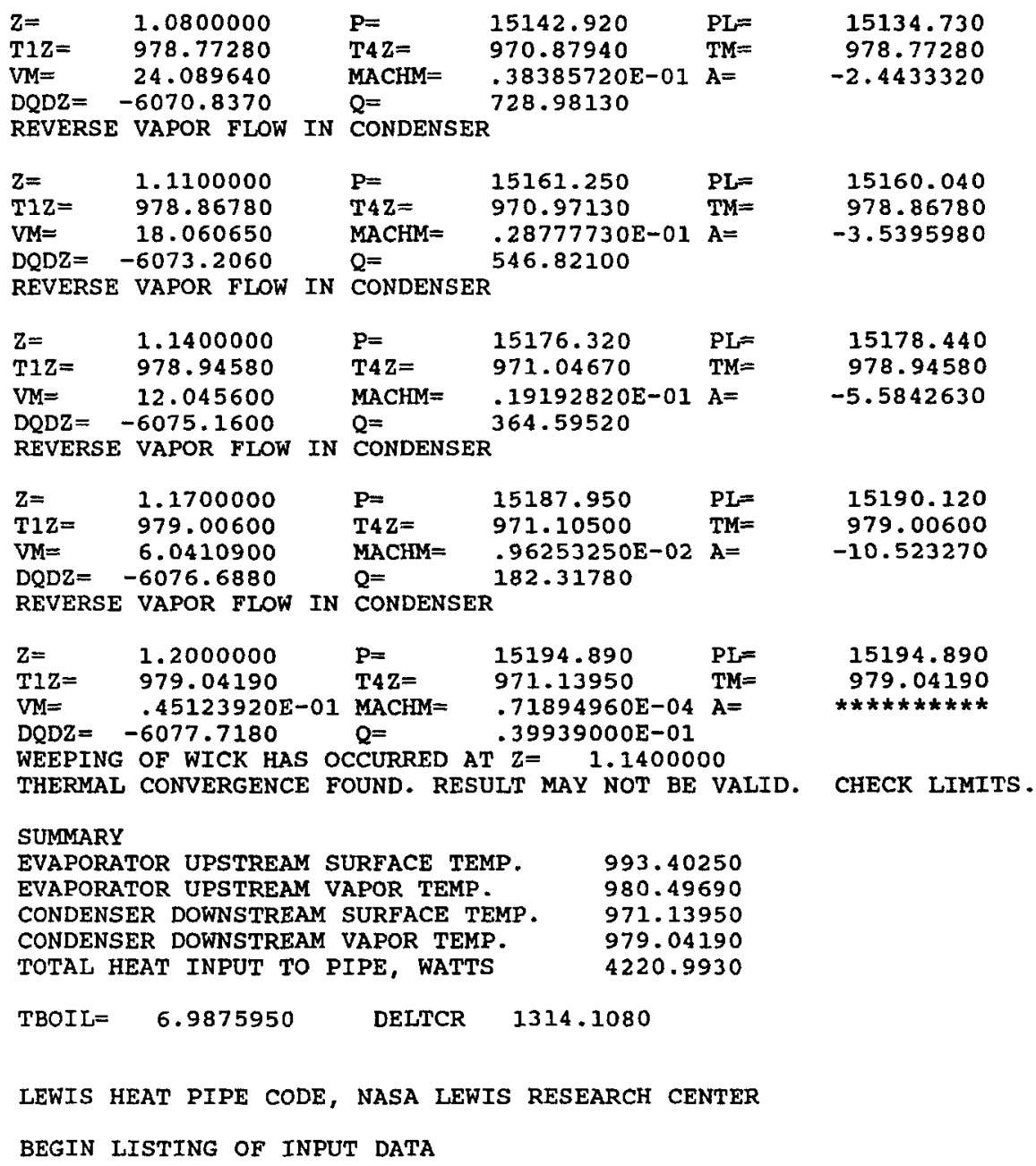




\section{APPENDIX E}

\section{SECOND EXAMPLE CASE}

A second example case that uses several options of the code differing from the previous case has been included. Figure 6 shows the boundary conditions for this case. An output from the computer code is also given. The input variables are listed with their appropriate values at the beginning of the output printout. This analysis is for a water heat pipe with an outside diameter of $4.13 \mathrm{~cm}$ and a screen wick with one artery.

The data summary at the end of the output shows that the pipe is operating very near the boiling limit computed by Marcus' equation (ref. 21). However, heat pipes of this general configuration but with much thicker screens have been run successfully in the laboratory. This illustrates the point that boiling theory, particularly with heat pipes, has not been sufficiently developed to provide accurate predictions of boiling onset. Experimental verification is required.

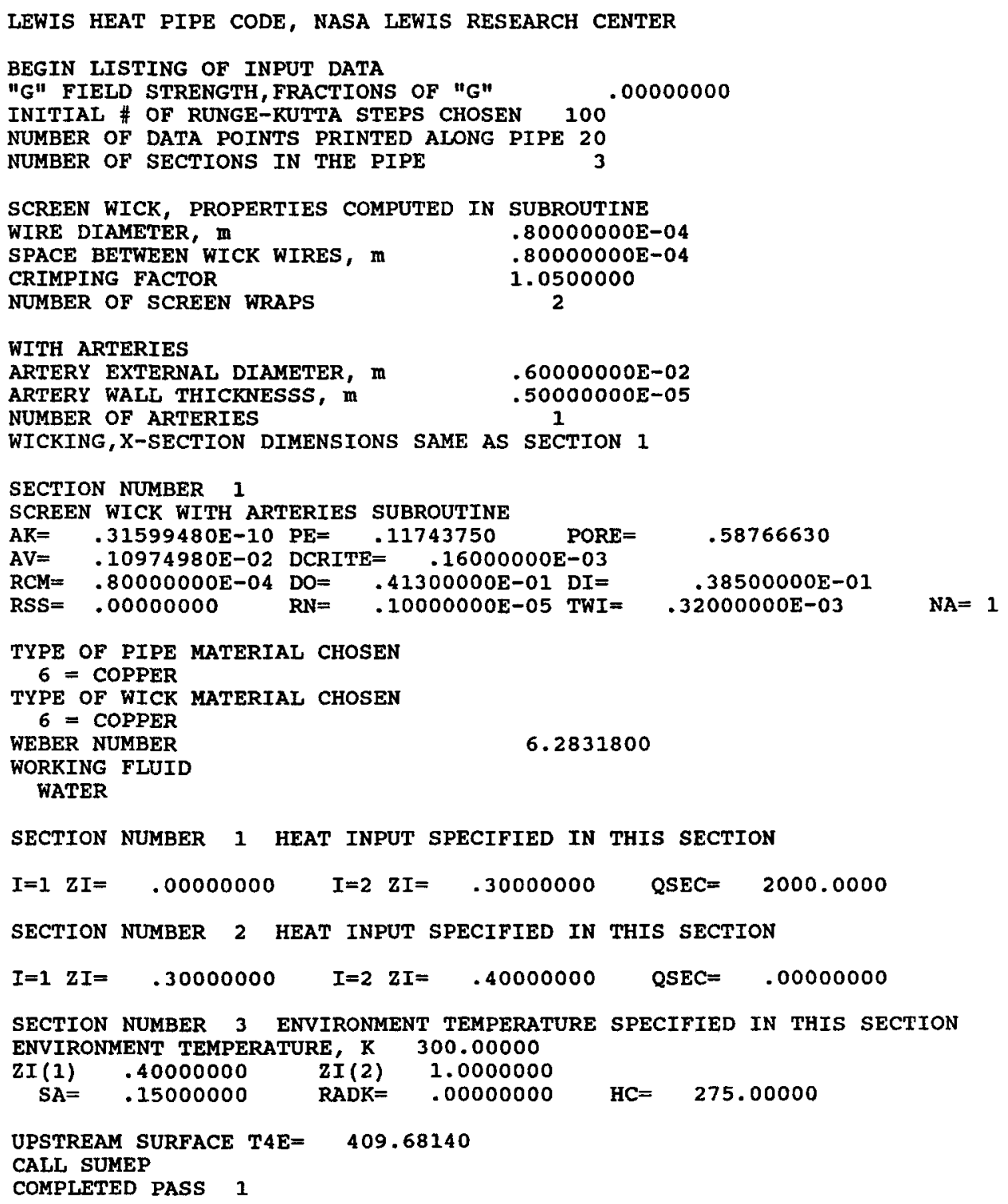




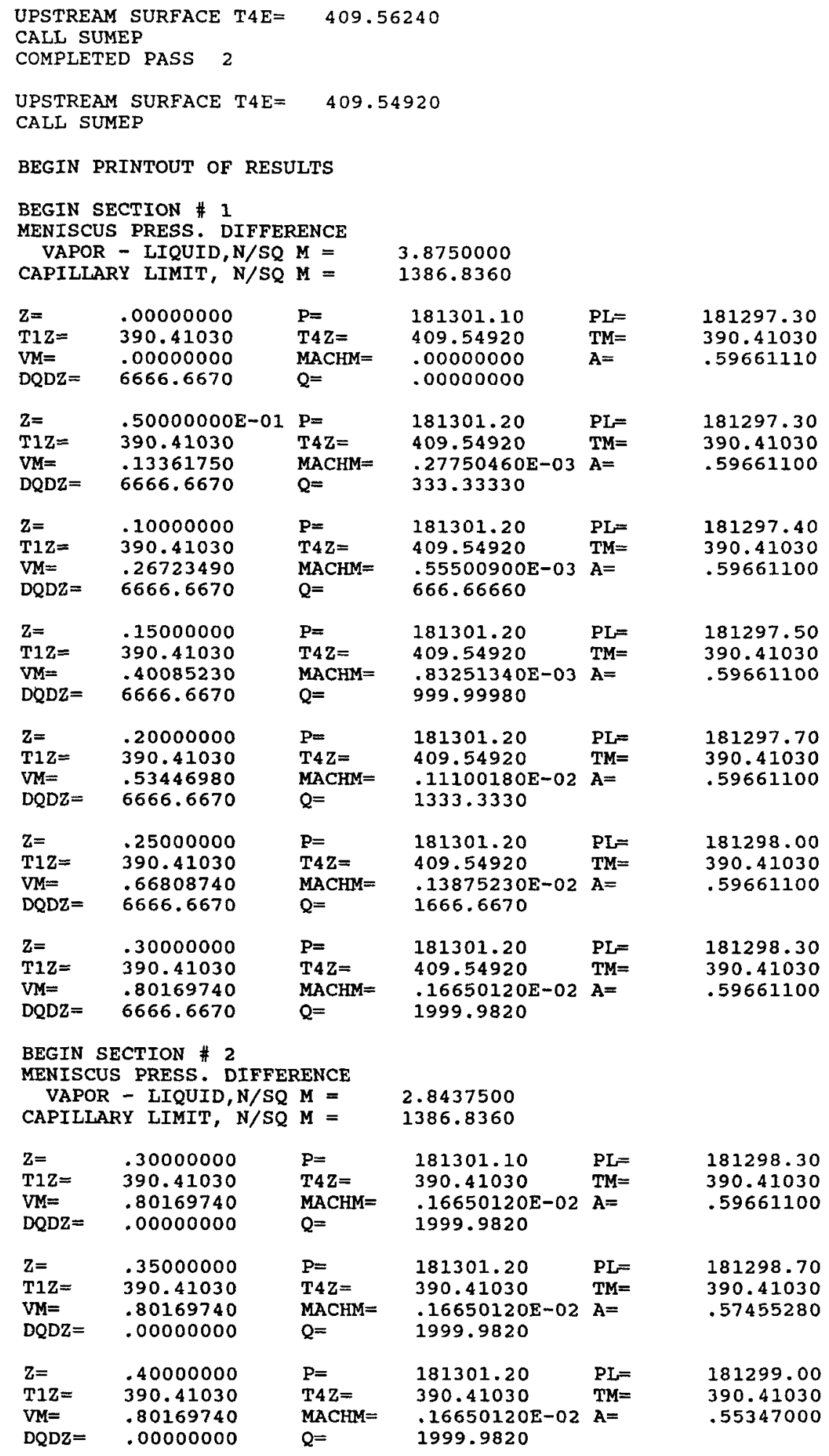


BEGIN SECTION \# 3 MENISCUS PRESS. DIFFERENCE

VAPOR - LIQUID, N/SQ $M=2.1250000$

CAPILIARY LIMIT, N/SQ M = 1386.8360

\begin{tabular}{|c|c|c|c|c|c|}
\hline $\begin{array}{l}Z= \\
T 1 Z= \\
V M= \\
D Q D Z=\end{array}$ & $\begin{array}{r}.40000000 \\
390.41030 \\
.80169740 \\
-3333.3060\end{array}$ & $\begin{array}{l}P= \\
\text { T4Z= } \\
\text { MACHM= } \\
Q=\end{array}$ & $\begin{array}{l}181301.10 \\
380.80740 \\
16650120 \mathrm{E}-02 \\
1999.9820\end{array}$ & $\begin{array}{l}\mathrm{PL}= \\
\mathrm{TM}= \\
\mathrm{A}=\end{array}$ & $\begin{array}{l}181299.00 \\
390.41030 \\
.55347000\end{array}$ \\
\hline $\begin{array}{l}Z= \\
T 1 Z= \\
V M= \\
D Q D Z=\end{array}$ & $\begin{array}{r}.45000000 \\
390.41030 \\
.73488940 \\
-3333.3050\end{array}$ & $\begin{array}{l}\mathrm{P}= \\
\mathrm{T} 4 \mathrm{Z}= \\
\mathrm{MACHM}= \\
\mathrm{Q}=\end{array}$ & $\begin{array}{l}181301.20 \\
380.80740 \\
.15262610 \mathrm{E}-02 \\
1833.3170\end{array}$ & $\begin{array}{l}P L= \\
T M= \\
A=\end{array}$ & $\begin{array}{l}181299.40 \\
390.41030 \\
.51142280\end{array}$ \\
\hline $\begin{array}{l}Z= \\
T 1 Z= \\
V M= \\
D Q D Z=\end{array}$ & $\begin{array}{r}50000000 \\
390.41030 \\
.66808130 \\
-3333.3050\end{array}$ & $\begin{array}{l}P= \\
\mathrm{T} 4 \mathrm{Z}= \\
\mathrm{MACHM}= \\
Q=\end{array}$ & $\begin{array}{l}181301.20 \\
380.80740 \\
113875100 \mathrm{E}-02 \\
1666.6520\end{array}$ & $\begin{array}{l}P L= \\
T M= \\
A=\end{array}$ & $\begin{array}{l}181299.70 \\
390.41030 \\
.45941780\end{array}$ \\
\hline $\begin{array}{l}Z= \\
\mathrm{T} 1 \mathrm{Z}= \\
\mathrm{VM}= \\
\mathrm{DQDZ}=\end{array}$ & $\begin{array}{r}.55000000 \\
390.41030 \\
.60127340 \\
-3333.3050\end{array}$ & $\begin{array}{l}P= \\
T 4 Z= \\
M A C H M= \\
Q=\end{array}$ & $\begin{array}{l}181301.20 \\
380.80740 \\
112487600 \mathrm{E}-02 \\
1499.9870\end{array}$ & $\begin{array}{l}P I= \\
T M= \\
A=\end{array}$ & $\begin{array}{l}181300.00 \\
390.41030 \\
.39382120\end{array}$ \\
\hline $\begin{array}{l}Z= \\
T 1 Z= \\
V M= \\
D Q D Z=\end{array}$ & $\begin{array}{r}.60000000 \\
390.41030 \\
.53446530 \\
-3333.3060\end{array}$ & $\begin{array}{l}\mathrm{P}= \\
\mathrm{T} 4 \mathrm{Z}= \\
\mathrm{MACHM}= \\
\mathrm{Q}=\end{array}$ & $\begin{array}{l}181301.20 \\
380.80740 \\
11100090 \mathrm{E}-02 \\
1333.3220\end{array}$ & $\begin{array}{l}\mathrm{PL}= \\
\mathrm{TM}= \\
\mathrm{A}=\end{array}$ & $\begin{array}{l}181300.20 \\
390.41030 \\
.30909930\end{array}$ \\
\hline $\begin{array}{l}Z= \\
T 1 Z= \\
V M= \\
D Q D Z=\end{array}$ & $\begin{array}{r}.65000000 \\
390.41030 \\
.46765730 \\
-3333.3060\end{array}$ & $\begin{array}{l}\mathrm{P}= \\
\mathrm{T} 4 \mathrm{Z}= \\
\mathrm{MACHM}= \\
\mathrm{Q}=\end{array}$ & $\begin{array}{l}181301.20 \\
380.80740 \\
.97125790 \mathrm{E}-03 \\
1166.6570\end{array}$ & $\begin{array}{l}P L= \\
T M= \\
A=\end{array}$ & $\begin{array}{l}181300.40 \\
390.41030 \\
.19644040\end{array}$ \\
\hline $\begin{array}{l}Z= \\
T 1 Z= \\
V M= \\
D Q D Z=\end{array}$ & $\begin{array}{r}.70000000 \\
390.41030 \\
.40084910 \\
-3333.3060\end{array}$ & $\begin{array}{l}P= \\
\mathrm{T} 4 \mathrm{Z}= \\
\mathrm{MACHM}= \\
\mathrm{Q}=\end{array}$ & $\begin{array}{l}181301.20 \\
380.80740 \\
.83250680 \mathrm{E}-03 \\
999.99170\end{array}$ & $\begin{array}{l}P L= \\
T M= \\
A=\end{array}$ & $\begin{array}{l}181300.60 \\
390.41030 \\
.41012880 \mathrm{E}-01\end{array}$ \\
\hline $\begin{array}{l}\mathrm{Z}= \\
\mathrm{T} 1 \mathrm{Z}= \\
\mathrm{VM}= \\
\mathrm{DQDZ}=\end{array}$ & $\begin{array}{r}.75000000 \\
390.41030 \\
.33404110 \\
-3333.3050\end{array}$ & $\begin{array}{l}\mathrm{P}= \\
\mathrm{TAZ}= \\
\mathrm{MACHM}= \\
\mathrm{Q}=\end{array}$ & $\begin{array}{l}181301.20 \\
380.80740 \\
.69375600 \mathrm{E}-03 \\
833.32670\end{array}$ & $\begin{array}{l}P L= \\
T M= \\
A=\end{array}$ & $\begin{array}{r}181300.80 \\
390.41030 \\
-.18400240\end{array}$ \\
\hline $\begin{array}{l}Z= \\
T 12= \\
V M= \\
D Q D Z=\end{array}$ & $\begin{array}{r}.80000000 \\
390.41030 \\
.26723300 \\
-3333.3050\end{array}$ & $\begin{array}{l}\mathrm{P}= \\
\mathrm{T} 4 \mathrm{Z}= \\
\mathrm{MACHM}= \\
\mathrm{Q}=\end{array}$ & $\begin{array}{l}181301.20 \\
380.80740 \\
.55500510 \mathrm{E}-03 \\
666.66160\end{array}$ & $\begin{array}{l}\mathrm{PL}= \\
\mathrm{TM}= \\
\mathrm{A}=\end{array}$ & $\begin{array}{r}181300.90 \\
390.41030 \\
-.53202300\end{array}$ \\
\hline $\begin{array}{l}\mathrm{Z}= \\
\mathrm{T} 1 \mathrm{Z}= \\
\mathrm{VM}= \\
\mathrm{DQDZ}=\end{array}$ & $\begin{array}{r}.85000000 \\
390.41030 \\
.20042490 \\
-3333.3050\end{array}$ & $\begin{array}{l}\mathrm{P}= \\
\mathrm{T} 4 \mathrm{Z}= \\
\mathrm{MACHM}= \\
\mathrm{Q}=\end{array}$ & $\begin{array}{l}181301.20 \\
380.80740 \\
.41625420 \mathrm{E}-03 \\
499.99660\end{array}$ & $\begin{array}{l}P L= \\
T M= \\
A=\end{array}$ & $\begin{array}{r}181301.00 \\
390.41030 \\
-1.1253170\end{array}$ \\
\hline $\begin{array}{l}Z= \\
T 1 Z= \\
V M= \\
\text { DQDZ= } \\
\text { REVERSE }\end{array}$ & $\begin{array}{r}.90000000 \\
390.41030 \\
.13361680 \\
-3333.3050 \\
\text { VAPOR FLOW IN }\end{array}$ & $\begin{array}{l}\mathrm{P}= \\
\mathrm{T} 4 \mathrm{Z}= \\
\mathrm{MACHM}= \\
\mathrm{Q}= \\
\text { CONDENSER }\end{array}$ & $\begin{array}{l}181301.20 \\
380.80740 \\
.27750310 \mathrm{E}-03 \\
333.33120\end{array}$ & $\begin{array}{l}\mathrm{PL}= \\
\mathrm{TM}= \\
\mathrm{A}=\end{array}$ & $\begin{array}{r}181301.10 \\
390.41030 \\
-2.3130040\end{array}$ \\
\hline $\begin{array}{l}\mathrm{Z}= \\
\mathrm{T} 1 \mathrm{Z}= \\
\mathrm{VM}= \\
\text { DQDZ= } \\
\text { REVERSE }\end{array}$ & $\begin{array}{l}.95000000 \\
390.41030 \\
.66808610 \mathrm{E}-01 \\
-3333.3050 \\
\text { VAPOR FLOW IN }\end{array}$ & $\begin{array}{l}\mathrm{P}= \\
\mathrm{T} 4 \mathrm{Z}= \\
\mathrm{MACHM}= \\
\mathrm{Q}= \\
\text { CONDENSER }\end{array}$ & $\begin{array}{l}181301.20 \\
380.80740 \\
.13875200 \mathrm{E}-03 \\
166.66600\end{array}$ & $\begin{array}{l}P L= \\
T M= \\
A=\end{array}$ & $\begin{array}{r}181301.20 \\
390.41030 \\
-5.6202380\end{array}$ \\
\hline $\begin{array}{l}\mathrm{Z}= \\
\mathrm{T} 1 \mathrm{Z}= \\
\mathrm{VM}= \\
\mathrm{DQDZ}=\end{array}$ & $\begin{array}{l}1.0000000 \\
390.41030 \\
.77493760 \mathrm{E}-05 \\
-3333.3060\end{array}$ & $\begin{array}{l}P= \\
T 4 Z= \\
M A C H M= \\
Q=\end{array}$ & $\begin{array}{l}181301.20 \\
380.80740 \\
.16094360 \mathrm{E}-07 \\
.18920090 \mathrm{E}-01\end{array}$ & $\begin{array}{l}P I= \\
T M= \\
A=\end{array}$ & $\begin{array}{r}181301.20 \\
390.41030 \\
* \star \star \star \star \star \star \star \star \star *\end{array}$ \\
\hline
\end{tabular}


SUMMARY

EVAPORATOR UPSTREAM SURFACE TEMP. 409.54920

EVAPORATOR UPSTREAM VAPOR TEMP. $\quad 390.41030$

CONDENSER DOWNSTREAM SURFACE TEMP. 380.80740

CONDENSER DOWNSTREAM VAPOR TEMP. 390.41030

TOTAL HEAT INPUT TO PIPE, WATTS 1999.9820

TBOIL $=18.944220 \quad$ DELTCR 19.055030

IEWIS HEAT PIPE CODE, NASA LEWIS RESEARCH CENTER

BEGIN LISTING OF INPUT DATA 


\section{APPENDIX F \\ BRIEF REVIEW OF HEAT PIPE LIMITS}

References 10,20 , and 21 contain information on heat pipe limits, from which the following material has been gleaned.

\section{Sonic Limit}

At the sonic limit the vapor flow at the end of the heat input section is choked. An approximate expression for the sonic limit derived by Busse is presented in reference 10. This expression neglects friction effects. There are two tests for choked flow in this code. One is a sign change of the determinant of the set of equations used to find the increment in the principal dependent variables $p, T_{m}$, and $A(z)$ for the next step of the Runge-Kutta solution. The other is the onset of an extreme negative temperature gradient (at choke the pressure gradient, and therefore the temperature gradient, is negatively infinite). These conditions occurring before the end of the heat input or adiabatic section cause the code to take corrective action.

\section{Capillary Limit}

The capillary limit is defined as the maximum pressure differential between vapor and liquid that the meniscus of the vapor-liquid interface can sustain before rupture. At the point where this occurs, liquid is no longer pumped to the surface. Dryout occurs and the pipe may overheat. The capillary limit is usually written as

$$
p_{v}-p_{l}=\frac{2 \sigma}{r_{e f f}}
$$

where

$p_{v} \quad$ vapor pressure

$p_{l} \quad$ liquid pressure

$\sigma$ liquid surface tension

$r_{\text {eff }}$ effective pore radius

The effective pore radius governing in cases where there is a gradation of pore sizes is taken to be the largest in the pipe region in question. Some wick structures are reputed to be tolerant of meniscus failure in some pores so that local dryout does not become a problem.

\section{Entrainment Limit}

Entrainment occurs when vapor shear forces lift liquid out of the wick and propel it back toward the condenser. The Weber number is customarily taken as the index of whether or not this will occur. The Weber number is defined as the ratio of inertial vapor forces attempting to dislodge the liquid to the surface tension forces restraining the liquid. One definition of the Weber number (ref. 20) is 


$$
\mathrm{We}=\frac{\rho v^{2} z_{c}}{\sigma}
$$

where

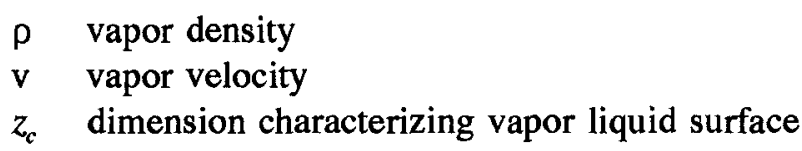

In wicked heat pipes the Weber number is related to the wick spacing. In this formulation, experimentation has shown that the critical Weber number at which droplets dislodge is generally between 2 and 3. A default value of 2 is employed in this code. The critical dimension $z_{r}$ is taken in this code as the effective pore size of the wicking for determining the capillary limit. For thermosyphons and wickless heat pipes, with which this code is not concerned, different expressions must be used. When the entrainment limit is encountered in the code, a message is printed out and execution continues. It is then up to the user to alter the pipe geometry or the operating conditions demanded, to correct the problem.

\section{Viscous Limit}

The vapor flow in the heat pipe is driven by the pressure drop between the evaporator and the condenser. At low evaporator temperatures and low power inputs a pressure may be reached at some point in the condenser that corresponds to the vapor pressure at the ambient or environment temperature. In a sense the viscous forces in the vapor have used up the pressure difference required to drive the vapor flow. As a result the full length of the condenser is not available for heat rejection. This condition is defined as the viscous limit. Because computation cannot continue, a message is printed, as are the data for the last completed step. In actual practice heat pipes can operate for extended periods at this condition before all the working fluid is lost to the inactive section.

\section{Boiling Limit}

Boiling in the wick occurs because of the temperature gradient established through the liquid in the wick when heat is being conducted. Inasmuch as the liquid-vapor interface is at saturation conditions, the liquid at the wall is superheated. Boiling would commence from nucleation sites consisting of pits or defects in the surface or the mesh openings themselves in the wick. If the sites are sufficiently small, surface tension enables the bubbles to resist the vapor pressure within them and they remain intact. At a sufficiently high temperature gradient and heat transfer rate, the bubble grows in diameter until it can no longer withstand the pressure. The bubble then detaches and rises to the surface. For determination of the boiling limit the code uses the equation presented by Marcus (ref. 21). The default size of the critical boiling dimension in the code is $10^{-6}$ meters. However, if a screen wick or a sintered wick is chosen (wick options $2,3,4$, and 5) the critical pore size is taken to be the effective pore size for determining the capillary limit. It must be pointed out that satisfactory information on the determination of the boiling limit is very sparse, so that a liberal factor of safety with respect to the limit must be used in all designs. If the boiling limit is encountered in operating the code, a message is printed out and computation continues. 


\section{Critical Point}

In some instances a set of boundary conditions may be presented for solution that will cause the pipe temperature to exceed the critical temperature for the working fluid. Inasmuch as the surface tension and the heat of vaporization vanish at the critical point, no solution is possible. Before the code begins execution, the initial estimate for T4E is compared with the critical temperature of the working fluid. If T4E exceeds an arbitrary 80 percent of critical temperature, a message is printed out and a new set of conditions is requested. 


\section{REFERENCES}

1. Woloshun, K.; Merrigan, M.A.; and Best, E.D.: HTPIPE: A Steady State Heat Pipe Analysis Program. Space Nuclear Power Systems, Vol. 9, M.S. El-Genk and M.D. Hoover, eds., Orbit Book Co., Malabar, FL, 1988, pp. 395-404.

2. McLennan, G.A.: ANL/HTP: A Computer Code for the Simulation of Heat Pipe Operation. Argonne National Laboratory, ANL-83-108, Nov. 1983.

3. Baker, K.W.; and Tower, L.K.: The NASA Lewis Heat Pipe Code With Application to SP-100 GES Heat Pipes. Space Nuclear Power Systems, Vol. 9, M.S. El-Genk and M.D. Hoover, eds., Orbit Book Company, Inc., Malabar, FL, 1988, pp. 387-394.

4. Busse, C.A.; and Prenger, F.C.: Numerical Analysis of the Vapor Flow in Cylindrical Heat Pipes. Research and Development of Heat Pipe Technology, K. Oshima, et al., eds., Japan Technology and Economics Center, Tokyo, Part 1, 1984, pp. 214-219.

5. DeMichele, D.W.: The Numerical Solution to Axial Symmetric Compressible Flow With Mass Injection and Its Application to Heat Pipes. Ph.D. Thesis, University of Arizona, 1970.

6. Press, W.H., et al.: Numerical Recipes: The Art of Scientific Computing. Cambridge University Press, Cambridge, 1986.

7. Ewing, C.T., et al.: Molecular Association in Sodium, Potassium, and Cesium Vapors at High Temperatures, J. Phys. Chem., vol. 71, no. 3, Feb. 1967, pp. 473-477.

8. McBride, B.J.; and Gordon, S.: FORTRAN IV Program for Calculation of Thermodynamic Data, NASA TN D-4097, 1967.

9. Foust, O.J., ed.: Sodium-NaK Engineering Handbook, Vol. 1, Sodium-Chemistry and Physical Properties. Gordon and Breach Science Publishers. Inc., New York, 1972.

10. Dunn, P.; and Reay, D. A.: Heat Pipes. Third Ed., Pergamon Press, 1982.

11. Brennan, P.J.; and Kroliczek, E.J.: Heat Pipe Design Handbook, Vols. 1 and 2, B \& K Engineering, Inc., NTIS N81-70113, 1979.

12. Rohsenow, W.M.; Hartnett, J.P.; and Ganic, E.N.: Handbook of Heat Transfer Fundamentals, 2nd Ed., McGraw-Hill, 1985.

13. Weast, R.C., ed.: CRC Handbook of Chemistry and Physics. 67th ed., CRC Press Inc., 1986.

14. Achener, P.Y., et al.: Thermophysical and Heat Transfer Properties of Alkali Metals. AGN-8195, Vol. 1, Aerojet-General Nucleonics, San Ramon, CA, 1968.

15. Boyer, H. E.; and Gall, T.L.: Metals Handbook. Desk Edition, American Society for Metals, 1985. 
16. Busse, C.A.: Pressure Drop in the Vapor Phase of Long Heat Pipes. IEEE Conference Record of the Thermionic Conversion Specialist Conference, IEEE, 1967, pp. 391-398.

17. Tower, L.K.; and Hainley, D.C.: An Improved Algorithm for the Modeling of Vapor Flow in Heat Pipes. NASA CR-185179, 1989.

18. Bowman, W.J.: Simulated Heat Pipe Vapor Dynamics. Ph.D. Dissertation, Air Force Institute of Technology, Wright Patterson Air Force Base, OH, 1987. (Avail. NTIS, AD-A182592.)

19. White, F.M.: Viscous Fluid Flow. McGraw-Hill, 1974.

20. Feldman, K.T.; and Thupvongsa, C.: Investigation of Counterflow Shear Effects in Heat Pipes. AIAA Paper 77-749, 1976.

21. Marcus, B.D.: Theory and Design of Variable Conductance Heat Pipes. NASA CR-2018, 1972.

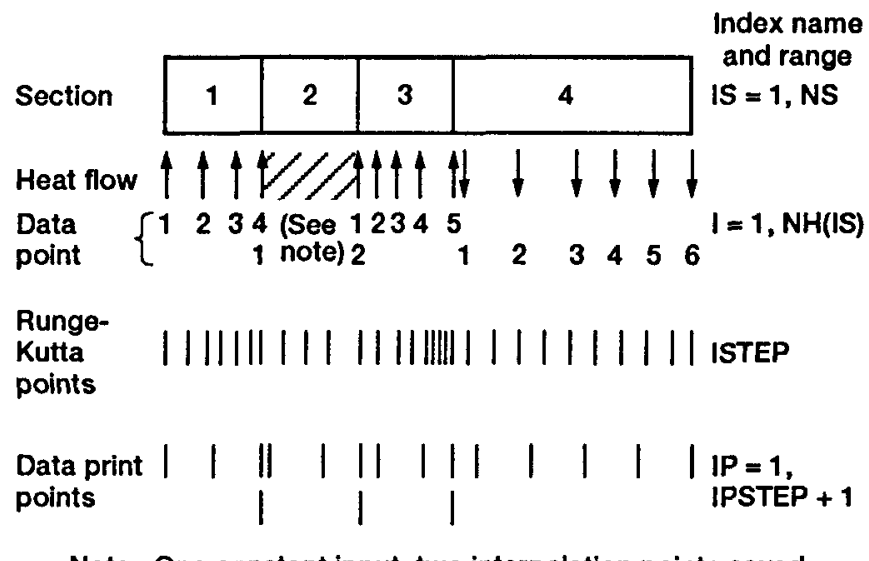

Note: One constant input, two interpolation points saved.

Figure 1.-Schematic of a heat pipe showing types of subdivisions in code.

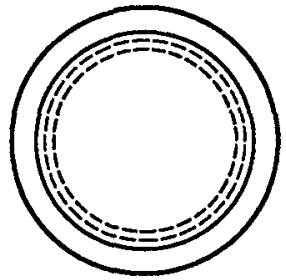

(a) Screen wick.

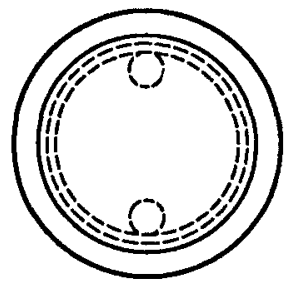

(b) Screen wick with arteries.

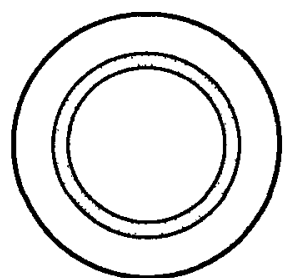

(c) Sintered metal.

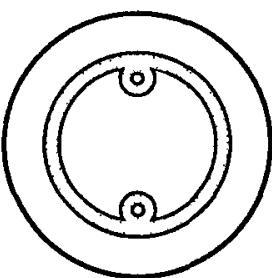

(d) Sintered metal with arteries.

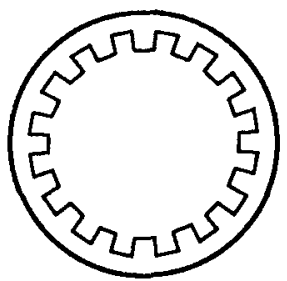

(e) Longitudinal grooves.

Figure 2.-Heat pipe wick structure options. 


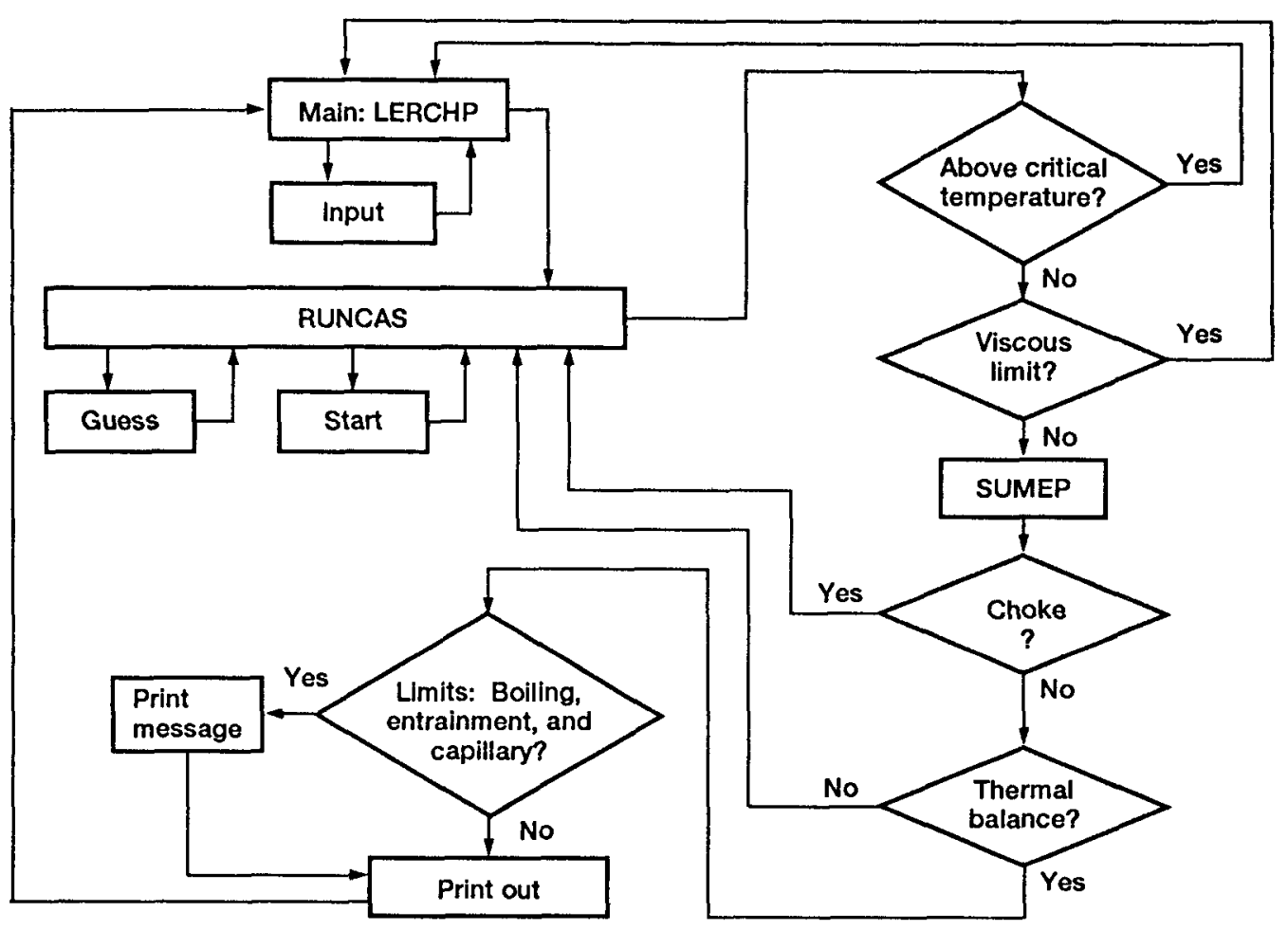

Figure 3.-Flow chart for NASA Lewis heat pipe code.

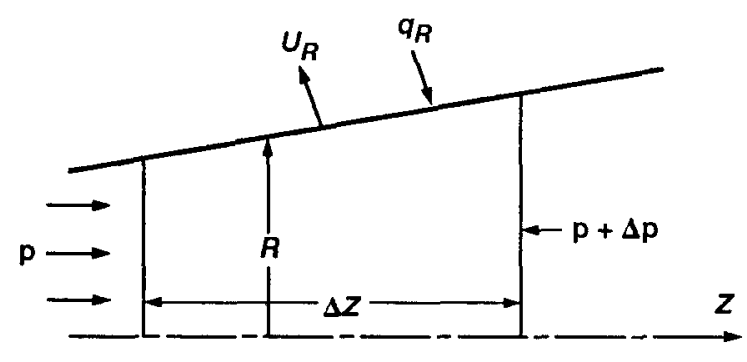

Figure 4.-Control volume for integral energy equation.

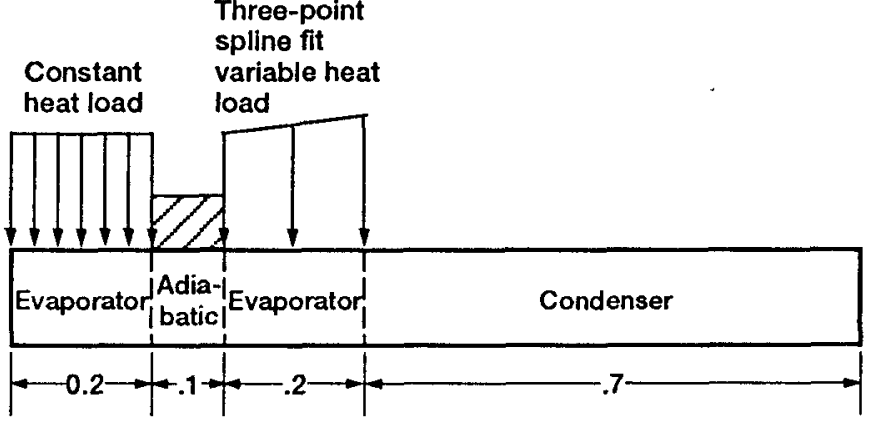

Figure 5.-Input heat loads for first example case. (Dimensions are in meters).

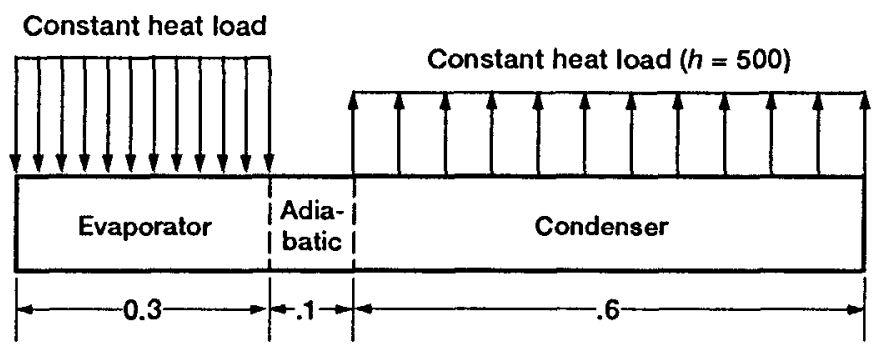

Figure 6.- Input heat loads for second example case. (Dimensions are in meters). 


\begin{tabular}{|c|c|c|c|}
\hline \multicolumn{3}{|c|}{ REPORT DOCUMENTATION PAGE } & $\begin{array}{l}\text { Form Approved } \\
\text { OMB No } 0704-0188\end{array}$ \\
\hline \multicolumn{4}{|c|}{ 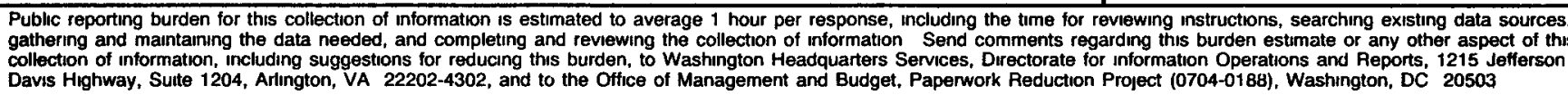 } \\
\hline 1. AGENCY USE ONLY (Leave blank) & $\begin{array}{r}\text { 2. REPORT DATE } \\
1992\end{array}$ & 3. $\mathrm{A}$ & $\begin{array}{l}\text { D DATES COVERED } \\
\text { echnical Memorandum }\end{array}$ \\
\hline \multicolumn{3}{|c|}{$\begin{array}{l}\text { 4. TITLE AND SUBTITLE } \\
\text { NASA Lewis Steady-State Heat Pipe Code } \\
\text { Users Manual }\end{array}$} & 5. FUNDING NUMBERS \\
\hline \multicolumn{3}{|c|}{$\begin{array}{l}\text { 6. AUTHOR(S) } \\
\text { Leonard K. Tower, Karl W. Baker, and Timothy S. Marks }\end{array}$} & $W U-390-13-21$ \\
\hline \multicolumn{3}{|c|}{$\begin{array}{l}\text { National Aeronautics and Space Administration } \\
\text { Lewis Research Center } \\
\text { Cleveland, Ohio } 44135-3191\end{array}$} & $\begin{array}{l}\text { 8. PERFORMING ORGANIZATION } \\
\text { REPORT NUMBER } \\
\text { E- } 6450\end{array}$ \\
\hline \multicolumn{3}{|c|}{$\begin{array}{l}\text { National Aeronautics and Space Administration } \\
\text { Washington, D.C. } 20546-0001\end{array}$} & $\begin{array}{l}\text { 10. SPONSORING/MONITORING } \\
\text { AGENCY REPORT NUMBER } \\
\text { NASA TM-105161 }\end{array}$ \\
\hline \multicolumn{4}{|c|}{$\begin{array}{l}\text { 11. SUPPLEMENTARY NOTES } \\
\text { Leonard K. Tower, Sverdrup Technology, Inc., Lewis Research Center Group, } 2001 \text { Aerospace Parkway, Brook Park, } \\
\text { Ohio 44142; Karl W. Baker, NASA Lewis Research Center; Timothy S. Marks, Oregon State University, Corvallis, } \\
\text { Oregon 97331. Responsible person, Karl W. Baker, (216) 433-6162. }\end{array}$} \\
\hline \multicolumn{3}{|c|}{$\begin{array}{l}\text { 12a. DISTRIBUTION/AVAILABILITY STATEMENT } \\
\text { Unclassified - Unlimited } \\
\text { Subject Category } 20\end{array}$} & 12b. DISTRIBUTION CODE \\
\hline
\end{tabular}

13. ABSTRACT (Maximum 200 words)

The NASA Lewis heat pipe code has been developed to predict the performance of heat pipes in the steady state. The code can be used as a design tool on a personal computer or, with a suitable calling routine, as a subroutine for a mainframe radiator code. A variety of wick structures, including a user input option, can be used. Heat pipes with multiple evaporators, condensers, and adiabatic sections in series and with wick structures that differ among sections can be modeled. Several working fluids can be chosen, including potassium, sodium, and lithium, for which the monomer-dimer equilibrium is considered. The code incorporates a vapor flow algorithm that treats compressibility and axially varying heat input. This code facilitates the determination of heat pipe operating temperatures and heat pipe limits that may be encountered at the specified heat input and environment temperature. Data are input to the computer through a user-interactive input subroutine. Output, such as liquid and vapor pressures and temperatures, is printed at equally spaced axial positions along the pipe as determined by the user.

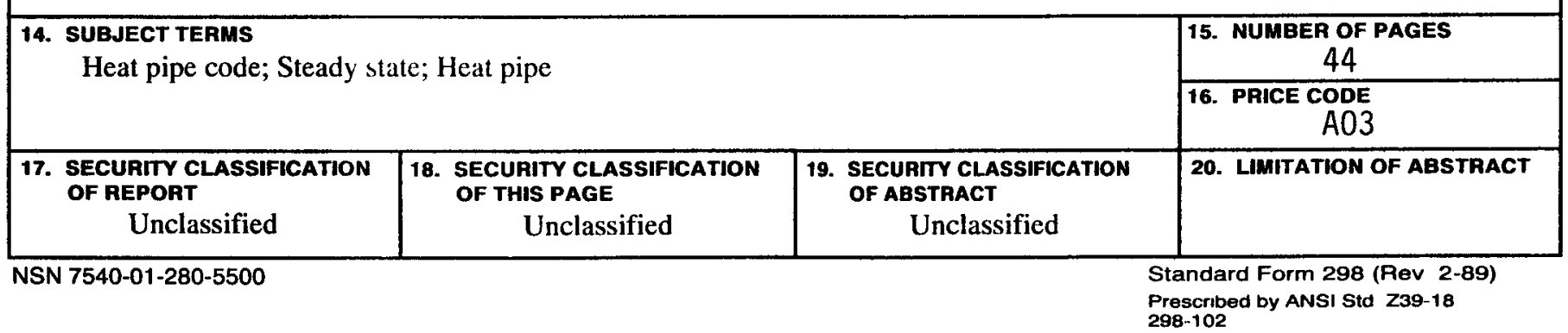


National Aeronautics and

Space Administration

Lewis Research Center

Cleveland, Ohio 44135
FOURTH CLASS MAIL

ADDRESS CORRECTION REQUESTED
Otficlel Buaines:

Penalty for Private Use $\mathbf{\$ 3 0 0}$

Posiage and Fees Pard

Natıonal Aeronautics and

Space Administration

NASA 451 